\title{
Understanding the optical properties of ambient sub- and supermicron particulate matter: results from the CARES 2010 field study in northern California
}

\author{
Christopher D. Cappa ${ }^{1}$, Katheryn R. Kolesar ${ }^{1, a}$, Xiaolu Zhang ${ }^{1}$, Dean B. Atkinson ${ }^{2}$, Mikhail S. Pekour ${ }^{3}$, \\ Rahul A. Zaveri ${ }^{3}$, Alla Zelenyuk ${ }^{4}$, and Qi Zhang ${ }^{5}$ \\ ${ }^{1}$ Department of Civil and Environmental Engineering, University of California, Davis, CA 95616, USA \\ ${ }^{2}$ Department of Chemistry, Portland State University, Portland, OR 92707, USA \\ ${ }^{3}$ Atmospheric Sciences \& Global Change Division, Pacific Northwest National Laboratory, Richland, WA 99352, USA \\ ${ }^{4}$ Physical Sciences Division, Pacific Northwest National Laboratory, Richland, WA 99352, USA \\ ${ }^{5}$ Department of Environmental Toxicology, University of California, Davis, CA 95616, USA \\ a now at: Department of Chemistry, University of Michigan, Ann Arbor, MI 48109, USA
}

Correspondence to: Christopher D. Cappa (cdcappa@ucdavis.edu)

Received: 15 November 2015 - Published in Atmos. Chem. Phys. Discuss.: 18 January 2016

Revised: 30 April 2016 - Accepted: 5 May 2016 - Published: 27 May 2016

\begin{abstract}
Measurements of the optical properties (absorption, scattering and extinction) of $\mathrm{PM}_{1}, \mathrm{PM}_{2.5}$ and $\mathrm{PM}_{10}$ made at two sites around Sacramento, CA, during the June 2010 Carbonaceous Aerosols and Radiative Effects Study (CARES) are reported. These observations are used to establish relationships between various intensive optical properties and to derive information about the dependence of the optical properties on photochemical aging and sources. Supermicron particles contributed substantially to the total light scattering at both sites, about $50 \%$ on average. A strong, linear relationship is observed between the scattering Ångström exponent for $\mathrm{PM}_{10}$ and the fraction of the scattering that is contributed by submicron particles $\left(f_{\text {sca, } \mathrm{PM}_{1}}\right)$ at both sites and with similar slopes and intercepts (for a given pair of wavelengths), suggesting that the derived relationship may be generally applicable for understanding variations in particle size distributions from remote sensing measurements. At the more urban T0 site, the $f_{\text {sca, } \mathrm{PM}_{1}}$ increased with photochemical age, whereas at the downwind, more rural T1 site the $f_{\text {sca, } \mathrm{PM}_{1}}$ decreased slightly with photochemical age. This difference in behavior reflects differences in transport, local production and local emission of supermicron particles between the sites. Light absorption is dominated by submicron particles, but there is some absorption by supermicron particles ( $\sim 15 \%$ of the total). The supermi-
\end{abstract}

cron absorption derives from a combination of black carbon that has penetrated into the supermicron mode and from dust, and there is a clear increase in the mass absorption coefficient of just the supermicron particles with increasing average particle size. The mass scattering coefficient (MSC) for the supermicron particles was directly observed to vary inversely with the average particle size, demonstrating that MSC cannot always be treated as a constant in estimating mass concentrations from scattering measurements, or vice versa. The total particle backscatter fraction exhibited some dependence upon the relative abundance of sub- versus supermicron particles; however this was modulated by variations in the median size of particles within a given size range; variations in the submicron size distribution had a particularly large influence on the observed backscatter efficiency and an approximate method to account for this variability is introduced. The relationship between the absorption and scattering Ångström exponents is examined and used to update a previously suggested particle classification scheme. Differences in composition led to differences in the sensitivity of $\mathrm{PM}_{2.5}$ to heating in a thermodenuder to the average particle size, with more extensive evaporation (observed as a larger decrease in the $\mathrm{PM}_{2.5}$ extinction coefficient) corresponding to smaller particles; i.e., submicron particles were generally more susceptible to heating than the supermicron particles. The influence 
of heating on the particle hygroscopicity varied with the effective particle size, with larger changes observed when the $\mathrm{PM}_{2.5}$ distribution was dominated by smaller particles.

\section{Introduction}

Atmospheric aerosol particles impact regional and global climate by scattering and absorbing solar radiation, as well as by affecting the properties of clouds, although the magnitude of these impacts remains uncertain (IPCC, 2013). The specific ability of particles to interact with solar radiation is dependent upon particle size, morphology and composition (Bohren and Huffman, 1998), which are often linked through variations in sources and chemical processing. Atmospheric particles span a wide range of sizes, from just a few nanometers to many microns. Quantitative understanding of the absolute and relative contributions across this entire size range is necessary to assess their climate impacts (Schwartz, 1996). The major sources of particles within the submicron and supermicron size regimes differ, with submicron particles generally deriving from combustion emissions and secondary formation and supermicron particles generally coming from mechanical action (e.g., wind-blown dust or ocean wave breaking) (Seinfeld and Pandis, 1998). As such, particle composition varies across this size range, as does the effectiveness with which particles absorb and scatter solar radiation. In situ measurements of the wavelength- and sizedependent light scattering and absorption properties of ambient atmospheric particles made concurrent with measurements of the size-dependent particle composition can provide insights into the impacts of particles on local climate and air quality (Anderson et al., 2003; Jung et al., 2009), as well as into the more general relationships between particle size, composition and radiative effects that determine their global impacts (Quinn et al., 2004; Bates et al., 2006; Wang et al., 2007; Garland et al., 2008; Gyawali et al., 2009; Yang et al., 2009). Such in situ measurements can help to interpret observations from remote sensing (Russell et al., 2010; Giles et al., 2012) and to provide observational constraints for results from simulations using regional and global models (Kaufman et al., 2002; Myhre et al., 2012; Tsigaridis et al., 2014). Measurements of particulate mass concentrations and composition for $\mathrm{PM}_{2.5}$ and $\mathrm{PM}_{10}$ have become routine through networks such as the US Interagency Monitoring of Protected Visual Environments (IMPROVE) network (Malm et al., 2007), and these can be used to "reconstruct" aerosol optical properties (Malm and Hand, 2007). However, direct measurements of the optical properties of particles between different size regimes are much less common, and where they do exist are quite often made in the marine boundary layer (e.g., Bates et al., 2006) and not over land. $\left(\mathrm{PM}_{2.5}\right.$ and $\mathrm{PM}_{10}$ refer to particulate matter with aerodynamic diameters below 2.5 and $10 \mu \mathrm{m}$, respectively.)
The US Department of Energy Carbonaceous Aerosols and Radiative Effects Study (CARES) took place in June 2010 with a motivation of improving our understanding of aerosol optical properties and how they evolve in the atmosphere through observations (Zaveri et al., 2012). Two heavily instrumented ground observational sites were set up, one within the greater Sacramento, CA, urban area, and one approximately $40 \mathrm{~km}$ to the northeast in much more rural Cool, CA (Fig. S1 in the Supplement). At both sites a variety of aerosol particle physical, chemical and optical property measurements were made. These two sites were chosen because of the generally reproducible wind patterns that, much of the time, bring air up from the San Francisco Bay Area ( $\sim 160 \mathrm{~km} \mathrm{SW})$ and past the Sacramento urban core before continuing up towards the foothills of the Sierra Nevada where the air mass accumulates biogenic emissions during the day, with a reversed flow at night, bringing more biogenically influenced air down from the mountains. In this way, comparison between the two sites facilitates understanding of the role that atmospheric photochemical processing plays in altering particle optical properties.

Results from measurements of dry particle light scattering and absorption made for submicron particulate matter $\left(\mathrm{PM}_{1}\right)$ and for PM smaller than $10 \mu \mathrm{m}\left(\mathrm{PM}_{10}\right)$ at both sites and of dry particle light absorption and extinction for PM smaller than $2.5 \mu \mathrm{m}\left(\mathrm{PM}_{2.5}\right)$ at just the urban Sacramento site are reported in this study. The separate $\mathrm{PM}_{1}$ and $\mathrm{PM}_{10}$ measurements allow for determination of the optical properties of both submicron and supermicron $(\mathrm{PM}>1 \mu \mathrm{m})$ particles. The distinct sub- and supermicron measurements are used here to characterize and examine the variability in their relative contributions as well as the differences between their properties and sources in the summertime Sacramento region. A previous analysis of particle size distributions measured during the CARES campaign indicated a large contribution of supermicron aerosol to the total particle scattering (Kassianov et al., 2012). Here, direct measurements of the scattering by these supermicron particles are reported, and their sources and properties and the factors that drive their variability are examined.

These regional results are also used to develop more general understanding of the size- and composition-dependent variability in aerosol particle optical properties. The analysis here focuses especially on quantifying and assessing the relationships between various intensive optical parameters (such as the scattering Ångström exponent, the absorption Ångström exponent, and the single scatter albedo) or between these parameters and characteristics of the particle distribution (such as the fine-mode fraction or characteristic particle diameter) and how these differ between size ranges (sub- versus supermicron) or are influenced by photochemical aging or heating. Results from in situ measurements such as these here can help to inform remote sensing retrievals and climatologies, which can provide a much broader spatial picture of sub- versus supermicron abundances and contribu- 
Table 1. Table of instrumentation.

\begin{tabular}{|c|c|c|}
\hline Instrument & Property measured & Site \\
\hline $\begin{array}{l}\text { UCD Photoacoustic } \\
\text { Spectrometer (PAS) }\end{array}$ & Dry $\mathrm{PM}_{2.5}$ light absorption at 405 and $532 \mathrm{~nm}$ & T0 \\
\hline $\begin{array}{l}\text { UCD cavity ring-down } \\
\text { spectrometer }(\text { CRDS })^{\mathrm{a}}\end{array}$ & $\begin{array}{l}\text { Dry } \mathrm{PM}_{2.5} \text { light extinction at } 405 \text { and } 532 \mathrm{~nm} \text {; } \\
\text { humidified particle extinction at } 532 \mathrm{~nm}\end{array}$ & T0 \\
\hline $\begin{array}{l}\text { Particle Soot Absorption } \\
\text { Photometer (PSAP) }\end{array}$ & $\begin{array}{l}\text { Dry } \mathrm{PM}_{1} \text { and } \mathrm{PM}_{10} \text { light absorption at } 470,532 \\
\text { and } 660 \mathrm{~nm}\end{array}$ & $\mathrm{~T} 0, \mathrm{~T} 1$ \\
\hline Nephelometer ${ }^{b}$ & $\begin{array}{l}\text { Dry } \mathrm{PM}_{1} \text { and } \mathrm{PM}_{10} \text { light scattering at } 450,550 \\
\text { and } 700 \mathrm{~nm}\end{array}$ & T0, T1 \\
\hline $\begin{array}{l}\text { Aerodyne High-Resolution } \\
\text { Time-of-Flight Aerosol Mass } \\
\text { Spectrometer (HR-ToF-AMS) }\end{array}$ & $\begin{array}{l}\text { Non-refractory } \mathrm{PM}_{1} \text { composition }\left(\mathrm{NR}-\mathrm{PM}_{1}\right) \text {; organic } \\
\text { aerosol types through positive matrix factor analysis }\end{array}$ & T0, T1 \\
\hline $\begin{array}{l}\text { PNNL Single Particle Laser } \\
\text { Ablation Time-of-Flight Mass } \\
\text { Spectrometer (SPLAT-II) }\end{array}$ & $\begin{array}{l}\text { Single particle composition and identification for } \\
\mathrm{PM}_{0.05}-\mathrm{PM}_{2} \text { (optimized for } \mathrm{PM}_{0.1-0.6} \text { ) }\end{array}$ & T0 \\
\hline $\begin{array}{l}\text { Particle Ablation Laser- } \\
\text { desorption Mass Spectrometer } \\
\text { (PALMS) }\end{array}$ & $\begin{array}{l}\text { Single particle composition and identification for } \\
\mathrm{PM}_{0.15}-\mathrm{PM}_{2}\end{array}$ & $\mathrm{~T} 1$ \\
\hline $\begin{array}{l}\text { Single Particle Soot } \\
\text { Photometer (SP2) }\end{array}$ & $\begin{array}{l}\text { Refractory black carbon (rBC) number and mass } \\
\text { concentration and size distributions }\end{array}$ & T0, T1 \\
\hline $\begin{array}{l}\text { Scanning Mobility Particle } \\
\text { Sizer (SMPS) }\end{array}$ & $\mathrm{PM}_{1}$ particle mobility size distributions & T0, T1 \\
\hline $\begin{array}{l}\text { Aerodynamic Particle Sizer } \\
\text { (APS) }\end{array}$ & $\mathrm{PM}_{0.7}-\mathrm{PM}_{10}$ aerodynamic size distributions & T0, T1 \\
\hline $\mathrm{NO}_{x}$ chemiluminescence & $\mathrm{NO}+\mathrm{NO}_{2}$ (gas-phase) & T0 \\
\hline $\begin{array}{l}\mathrm{NO}_{y} \text { by thermal conversion } \\
\text { and chemiluminescence }\end{array}$ & $\begin{array}{l}\text { Nitrogen oxides }\left(\mathrm{NO}+\mathrm{NO}_{2}+\mathrm{HNO}_{3}+\text { alkyl nitrates }\right. \\
+ \text { peroxy nitrates })\end{array}$ & T0 \\
\hline $\begin{array}{l}\text { Proton Transfer Reaction } \\
\text { Mass Spectrometer (PTR-MS) }\end{array}$ & $\begin{array}{l}\text { Concentrations of select volatile organic compounds } \\
\text { (specifically, benzene and toluene) }\end{array}$ & T0, T1 \\
\hline
\end{tabular}

tions to light scattering and extinction (Dubovik et al., 2002; Eck et al., 2010).

\section{Experimental}

All measurements were made during the 2010 CARES study, which took place in the Sacramento, CA region, from 229 June 2010. Measurements were made at one of two sites: one located in the greater Sacramento urban region (termed the T0 site) and one located $\sim 40 \mathrm{~km}$ northeast downwind in Cool, CA (termed the T1 site), shown in Fig. S1. The CARES study has previously been described in detail (Fast et al., 2012; Zaveri et al., 2012), and only a brief overview is given here. A list of instrumentation used in this study is given in Table 1, an overview schematic of the sampling con- figuration in Fig. S2 and a list of abbreviations and symbols in Table S1 in the Supplement.

\subsection{Measurements at the T0 site}

Particle light absorption coefficients $\left(b_{\mathrm{abs}}\right)$ were measured using the UC Davis (UCD) Photoacoustic Spectrometer (PAS) at 405 and $532 \mathrm{~nm}$ (Lack et al., 2012) and using a Particle Soot Absorption Photometer (PSAP; Radiance Research, Inc.) at 470, 532 and $660 \mathrm{~nm}$ (Bond et al., 1999; Virkkula et al., 2005). The PAS measured light absorption for $\mathrm{PM}_{2.5}$ sampled through a cyclone, alternating on a 2.5 or 5 min timescale between bypass measurements (i.e., dried ambient particles) and measurements behind a constanttemperature $\left(225^{\circ} \mathrm{C}\right)$ thermodenuder (Huffman et al., 2008; Cappa et al., 2012) with a residence time of $5 \mathrm{~s}$. The PAS was 
calibrated before, during and after the study by referencing the observed photoacoustic response to added ozone to the extinction measured at the same wavelengths via cavity ringdown spectroscopy (CRDS) (Lack et al., 2012). The PSAP measured $b_{\mathrm{abs}}$ for $\mathrm{PM}_{1}$ or $\mathrm{PM}_{10}$ on an alternating 6 min cycle. The PSAP was corrected for spot size, flow and particle scattering using standard methods (Bond et al., 1999; Ogren, 2010). Light scattering and backscattering coefficients $\left(b_{\text {sca }}\right.$ and $b_{\text {bsca }}$, respectively) were measured for dried particles using a three-wavelength total/backscatter nephelometer (TSI, Model 3563) at 450, 550 and $700 \mathrm{~nm}$. The nephelometer sampled $\mathrm{PM}_{1}$ and $\mathrm{PM}_{10}$ on the same alternating 6 min cycle as the PSAP. The $b_{\text {sca }}$ and $b_{\text {bsca }}$ were corrected for truncation error (Anderson and Ogren, 1998). Light extinction coefficients $\left(b_{\mathrm{ext}}=b_{\mathrm{abs}}+b_{\mathrm{sca}}\right)$ were directly measured for $\mathrm{PM}_{2.5}$ using the UCD aerosol CRDS (Langridge et al., 2011; Cappa et al., 2012). The $b_{\text {ext }}$ were measured for dried particles at both 405 and $532 \mathrm{~nm}$, and at $532 \mathrm{~nm}$ measurements were additionally made for particles exposed to elevated relative humidity $(\mathrm{RH})(\sim 85 \%)$. The air sample was humidified by passing it through a custom humidifier, which consisted of a semi-permeable capillary membrane (Accurel) that was kept continuously wetted. The relative humidity in the CRD cells was monitored using Vaisala RH probes (HMP50) that were calibrated using saturated salt solutions. As with the UCD PAS, the CRDS operated behind a thermodenuder on a 2.5 or $5 \mathrm{~min}$ cycle. Measurements made through the thermodenuder were corrected for thermophoretic losses (Huffman et al., 2008; Cappa et al., 2012). PSAP and nephelometer measurements were made over the period 3-28 June 2010, with a data gap in the period 16-20 June. The CRD measurements and PAS measurements at $405 \mathrm{~nm}$ were made starting 20:00 PDT on 16 June through 09:00 PDT on 29 June. Due to a laser malfunction, the PAS measurements at $532 \mathrm{~nm}$ started at 12:00 PDT on 19 June. The thermodenuder measurements began at 12:00 PDT on 20 June.

Particle mobility diameter $\left(d_{\mathrm{p}, \mathrm{m}}\right)$ size distributions from 12.2 to $736.5 \mathrm{~nm}$ were measured using a Scanning Mobility Particle Sizer (SMPS; TSI Model 3080). Particle aerodynamic diameter $\left(d_{\mathrm{p}, \mathrm{a}}\right)$ size distributions from $542 \mathrm{~nm}$ to $19810 \mathrm{~nm}$ were measured using an Aerodynamic Particle Sizer (APS TSI Model 3321). The APS size distributions were converted to mobility-equivalent size distributions, assuming spherical particles and an effective particle material density of $2.0 \mathrm{~g} \mathrm{~cm}^{-3}$ and accounting for the Cunningham slip correction (DeCarlo et al., 2004). The use of an effective material density of $2.0 \mathrm{~g} \mathrm{~cm}^{-3}$ implicitly assumes that the larger particles characterized by the APS were primarily dust or sea spray. The resulting APS distribution was merged with the SMPS distribution to generate a time series of the mobility size distributions with sizes over the entire range $(12.2-19810 \mathrm{~nm})$. Because the $\mathrm{PM}_{1}, \mathrm{PM}_{2.5}$ and $\mathrm{PM}_{10}$ designations are associated with aerodynamic diameters, mobility-equivalent cut-diameters must be determined. The mobility-equivalent cut-diameters are (assuming a den- sity of $2 \mathrm{~g} \mathrm{~cm}^{-3}$ ) approximately 700,1750 and $7200 \mathrm{~nm}$, respectively. (For simplicity, we will continue to refer to the sub- and supermicron particle ranges based on the aerodynamic size.) The merged size distribution was truncated to an upper limit of $7200 \mathrm{~nm}$, and the campaign average for the T0 site is shown for reference in Fig. S3. One complication at the T0 site is that the APS did not collect data from 13:30 PDT on 22 June onwards, and thus information about the supermicron particle size distribution and mass concentrations is not available after this date.

Particle composition was monitored at T0 using the Single Particle Laser Ablation Time-of-Flight Mass Spectrometer (SPLAT-II) from 3 to 28 June (Zelenyuk et al., 2009). SPLAT-II characterizes the composition of individual particles and can be used to build a statistical picture of the distribution of particle types, as defined by the uniqueness of and similarities between their mass spectra (Zelenyuk et al., 2008). Analysis of the single particle mass spectra from SPLAT-II indicates a diversity of particle types, including dust, sea-salt-containing (SS), combustion-derived (including particles categorized as soot, biomass burning - $\mathrm{BB}$, primary organic - POA and hydrocarbon - HC), aminecontaining, and mixed sulfate/organic. SPLAT-II samples particles between $\sim 50 \mathrm{~nm}$ and $2 \mu \mathrm{m}$, although the sampling efficiency varies with particle size and with particle shape. SPLAT-II is optimized for particles with vacuum aerodynamic diameters $\left(d_{\mathrm{va}}\right)$ between 100 and $600 \mathrm{~nm}$, and detects larger particles with reduced relative efficiency.

Non-refractory submicron particulate matter (NR-PM) composition was measured using an Aerodyne HighResolution Time-of-Flight Aerosol Mass Spectrometer (HRAMS) (Canagaratna et al., 2007). The NR-PM components measured include organics, sulfate, nitrate, ammonium and chloride. Data during the first week and a half of the campaign (3-12 June) are especially noisy due to instrumental problems. The AMS data were processed and NR-PM concentrations determined using standard methods, assuming a collection efficiency of $50 \%$. Positive matrix factorization was applied to the data set (Zhang et al., 2011) and three factors associated with the organic aerosol (OA) were determined. One of these was characterized as a more-oxidized OA factor (OOA) while two were characterized as less oxidized OA factors, which were most likely cooking- and traffic-related and will be collectively referred to here as the hydrocarbon-like OA factor (HOA)(Atkinson et al., 2015). Black carbon mass concentrations were measured with a Single Particle Soot Photometer (SP2; DMT) (Schwarz et al., 2006). The SP2 was calibrated using mobility-size-selected Aquadag particles, using a size-dependent particle density (Gysel et al., 2011). The reported concentrations have been multiplied by a factor of 1.53 to account for the difference in sensitivity of the SP2 to Aquadag compared with fullerene soot (R. Subramanian, personal communication, 2015), which is thought to be a reasonable proxy for diesel soot (Laborde et al., 2012a). This adjustment factor was de- 
termined from laboratory studies conducted after the CARES campaign. The CARES SP2 instruments measured black carbon (BC)-containing particles with volume-equivalent core diameters between 30 and $400 \mathrm{~nm}$, although quantification below $d_{\mathrm{p} \text {,ved }}<\sim 100 \mathrm{~nm}$ becomes generally more challenging and can vary between instruments (Laborde et al., $2012 b$ ). No adjustment of the reported concentrations for black carbon containing particles outside of the SP2 detection size range has been made; thus the reported concentrations may be underestimated (Cappa et al., 2014).

Gas-phase concentrations of the sum of $\mathrm{NO}$ and $\mathrm{NO}_{2}$ (i.e., $\mathrm{NO}_{x}$ ) and the sum of all nitrogen oxides (i.e., $\mathrm{NO}_{y}$ ) were measured using a two-channel chemiluminescence instrument (Air Quality Design, Inc, High Performance, 2Channel) in which $\mathrm{NO}_{2}$ is photolyzed to $\mathrm{NO}$ using a blue light photolytic converter and $\mathrm{NO}_{y}$ is converted to $\mathrm{NO}$ on a Mo catalyst. Gas-phase concentrations of hydrocarbons, in particular of toluene and benzene, were measured using a Proton Transfer Reaction Mass Spectrometer (PTR-MS). These measurements can be used to estimate the average photochemical age (PCA) of the air mass (Roberts et al., 1984), with

$\mathrm{PCA}_{\mathrm{NO}_{x}}=-\frac{1}{k_{r x n}[\mathrm{OH}]} \ln \left(\frac{\left[\mathrm{NO}_{x}\right]}{\left[\mathrm{NO}_{y}\right]}\right)$,

where $k_{r x n}$ is the reaction rate coefficient for the $\mathrm{OH}+\mathrm{NO}_{2}$ reaction $\left(7.9 \times 10^{-12} \mathrm{~cm}^{3}\right.$ molecules ${ }^{-1} \mathrm{~s}^{-1}$; Brown et al., 1999), and

$\mathrm{PCA}_{\mathrm{HC}}=\frac{\ln (\mathrm{ER})-\ln \left(\frac{\text { [benzene }]}{[\text { toluene }]}\right)}{\left(k_{\mathrm{b}}-k_{\mathrm{t}}\right)[\mathrm{OH}]}$,

where ER is the emission ratio between benzene and toluene, assumed here to be 3.2 (Warneke et al., 2007), and $k_{\mathrm{b}}$ and $k_{\mathrm{t}}$ are the reaction rate coefficients for reaction of benzene $\left(1 \times 10^{-12} \mathrm{~cm}^{3}\right.$ molecule $\left.\mathrm{e}^{-1} \mathrm{~s}^{-1}\right)$ and toluene $\left(5.7 \times 10^{-12} \mathrm{~cm}^{3}\right.$ molecule $\left.{ }^{-1} \mathrm{~s}^{-1}\right)$ with $\mathrm{OH}$, respectively (Atkinson et al., 2006). Although there are challenges in interpreting PCA estimates quantitatively due to e.g., mixing of different sources (Parrish et al., 2007) and weekend/weekday differences (Warneke et al., 2013), PCA nonetheless provides a useful estimate of the extent of photochemical processing.

\subsection{Measurements at the $\mathrm{T} 1$ site}

A similar suite of measurements were made at the T1 site to those at the T0 site, including light absorption at 470, 532, $660 \mathrm{~nm}$ by PSAP, light scattering at $450,550,700 \mathrm{~nm}$ by nephelometer, particle size by SMPS and APS and submicron particle composition by HR-AMS and SP2. The SMPS deployed at T1 (described in Setyan et al., 2014) measures particle number distribution in the range of $10-858 \mathrm{~nm}$ in $d_{\mathrm{p}, \mathrm{m}}$. Analysis of the HR-AMS data using positive matrix factorization identified two distinct OOA factors, one of which was mainly associated with biogenic emissions and the other representative of secondary organic aerosol (SOA) formed in photochemically processed urban emissions. HOA was also observed at $\mathrm{T} 1$ but it on average accounted for only $\sim 10 \%$ of the OA mass. Details on HR-AMS and SMPS measurements at $\mathrm{T} 1$ and associated data analysis are given in Setyan et al. $(2012,2014)$. The particle scattering and absorption measurements were made nearly continuously from 3 to 28 June 2010. Light absorption measurements were also made using different PAS instruments, although these are not utilized here. PTR-MS measurements of toluene and benzene are available from 3 to 28 June 2010. Although $\mathrm{NO}$ and $\mathrm{NO}_{y}$ measurements were made, $\mathrm{NO}_{x}$ was not measured. Thus, it is only possible to estimate PCA at the $\mathrm{T} 1$ site using the benzene-toluene method (Eq. 2).

One additional way in which particle composition was characterized at T1 was with a Particle Ablation Laserdesorption Mass Spectrometer (PALMS) (Cziczo et al., 2006). The PALMS is similar to the SPLAT-II in that single particle mass spectra are collected for particles between about $d_{\mathrm{p}, \mathrm{a}} 150 \mathrm{~nm}$ and $2 \mu \mathrm{m}$, which are used to build a statistical picture of particle types. Analysis of the single particle mass spectra from PALMS at the T1 site yielded the following particle types: dust (termed MinMet for mineralogical/meteoric), sea-salt-containing (SS), combustionderived (including particles categorized as soot, biomass burning (BB) or oil), mixed sulfate/organic and others. Results from the PALMS measurements have been previously reported in Zaveri et al. (2012).

\subsection{Derived particle properties}

Using the alternating (i.e., sequential) $\mathrm{PM}_{1}$ and $\mathrm{PM}_{10}$ measurements, the properties of supermicron particles specifically have been estimated from the difference between $\mathrm{PM}_{10}$ and $\mathrm{PM}_{1}$, with

$b_{x, \text { super }}=\frac{b_{x, \mathrm{PM}_{10}}(t-1)+b_{x, \mathrm{PM}_{10}}(t+1)}{2}-b_{x, \mathrm{PM}_{1}}(t)$,

where $x$ indicates absorption or scattering and where the $t$ values indicate the average concentration over each $6 \mathrm{~min}$ averaging period (i.e., the $\mathrm{PM}_{1}-\mathrm{PM}_{10}$ cycle time). The fraction of absorption or scattering from $\mathrm{PM}_{1}$ or supermicron PM is therefore defined as

$f_{x, \mathrm{PM}_{1}}=\frac{b_{x, \mathrm{PM}_{1}}}{b_{x, \mathrm{PM}_{10}}}$
$f_{x, \text { super }}=\frac{b_{x, \text { super }}}{b_{x, \mathrm{PM}_{10}}}$,

where $x$ again indicates absorption or scattering. These ratios give an indication of the contribution of submicron or supermicron particles to the total absorption or scattering; e.g., larger values of $f_{\mathrm{sca}, \mathrm{PM}_{1}}$ indicate greater dominance of the submicron particle mode in terms of total scattering. 
Light absorption measurements are used to determine the absorption Ångström exponent (AAE), which characterizes the wavelength dependence of absorption and is given as

$\operatorname{AAE}_{\lambda_{1}, \lambda_{2}}=-\frac{\log \left(\frac{b_{\mathrm{abs}, \lambda_{1}}}{b_{\mathrm{abs}, \lambda_{2}}}\right)}{\log \left(\frac{\lambda_{1}}{\lambda_{2}}\right)}$,

where $\lambda_{1}$ and $\lambda_{2}$ indicate different wavelengths. It is often assumed that "pure" black carbon (BC) particles have an AAE close to 1 and that values $>1$ indicate the presence of lightabsorbing organics (referred to as brown carbon, or $\mathrm{BrC}$ ) or dust, which tend to exhibit absorption that increases sharply as wavelength decreases (Lack and Cappa, 2010). The AAE is dependent upon the chosen wavelength pair. The specific wavelength pair used to calculate AAE will be indicated using the notation $\mathrm{AAE}_{\lambda_{1}-\lambda_{2}}$. A related property, the difference in the $\mathrm{PM}_{10}$ and $\mathrm{PM}_{1} \mathrm{AAE}$, can then be calculated:

$\Delta \mathrm{AAE}_{10-1}=\mathrm{AAE}_{\mathrm{PM}_{10}}-\mathrm{AAE}_{\mathrm{PM}_{1}}$.

The scattering Ångström exponent (SAE) is also commonly used to characterize the relative contributions from sub- and supermicron particles (Clarke and Kapustin, 2010), and is defined analogously to the AAE as

$\operatorname{SAE}_{\lambda_{1}, \lambda_{2}}=-\frac{\log \left(\frac{b_{\text {sca }, \lambda_{1}}}{b_{\text {sca }, \lambda_{2}}}\right)}{\log \left(\frac{\lambda_{1}}{\lambda_{2}}\right)}$.

Larger values of the SAE correspond to overall smaller particles, and have been calculated for $\mathrm{PM}_{1}, \mathrm{PM}_{10}$ and $\mathrm{PM}_{\text {super }}$. A similar parameter, the extinction Ångström exponent, EAE, can be calculated for $\mathrm{PM}_{2.5}$ using the measured $b_{\text {ext }}$ or for $\mathrm{PM}_{1}$ or $\mathrm{PM}_{10}$ using the sum of the $b_{\text {sca }}$ and $b_{\text {abs }}$.

The fraction of extinction due to scattering is characterized through the single scatter albedo (SSA), which can be written in multiple ways depending on whether $b_{\text {ext }}, b_{\text {abs }}$ or $b_{\text {sca }}$ were the directly measured properties:

$\mathrm{SSA}=\frac{b_{\mathrm{ext}}-b_{\mathrm{abs}}}{b_{\mathrm{ext}}}=\frac{b_{\mathrm{sca}}}{b_{\mathrm{ext}}}=\frac{b_{\mathrm{sca}}}{b_{\mathrm{sca}}+b_{\mathrm{abs}}}$.

The angular dependence of scattering is characterized through measurement of the backscatter coefficients, $b_{\text {bsca }}$. The fraction of light that is backscattered, relative to the total scattering, is calculated as

$f_{\text {bsca }}=\frac{b_{\text {bsca }}}{b_{\text {sca }}}$.

The backscatter fraction is an important climate-relevant parameter as particle radiative effects depend in part on the extent to which incoming solar radiation is reflected back to space versus absorbed within the Earth system. The backscatter fraction is commonly converted to an asymmetry parameter, $g_{\text {sca }}$, and the empirically derived relationship between these is (Andrews et al., 2006)

$$
\begin{aligned}
g_{\mathrm{sca}} & =-7.143889 \cdot f_{\mathrm{bsca}}^{3}+7.464439 \cdot f_{\mathrm{bsca}}^{2} \\
& -3.9356 \cdot f_{\mathrm{bsca}}+0.9893 .
\end{aligned}
$$

The asymmetry parameter is the intensity-weighted average of the cosine of the scattering angle and ranges from -1 (all backscatter) to 1 (all forward scatter).

Using the measurements made behind the thermodenuder at the T0 site (i.e., the PAS and CRD measurements), various ratios and differences can be determined. The ratio between the denuded and undenuded extinction (i.e., the fraction of extinction remaining for $\mathrm{PM}_{2.5}$ ) provides a measure of the particle volatility, with smaller values indicating more volatile particles:

$f_{\mathrm{ext}, \mathrm{TD}}=\frac{b_{\mathrm{ext}, \mathrm{TD}}}{b_{\mathrm{ext}, \mathrm{amb}}}=\frac{b_{\mathrm{ext}}(t-1)+b_{\mathrm{ext}}(t+1)}{2 b_{\mathrm{ext}}(t)}$,

where TD indicates the thermodenuded and amb indicates the ambient time periods, and the second equality shows how the sequential TD and ambient measurements were accounted for similar to Eq. (3). The change in particle hygroscopicity upon thermodenuding is calculated as

$\Delta \gamma_{\mathrm{RH}}=\gamma_{\mathrm{RH}, \mathrm{amb}}-\gamma_{\mathrm{RH}, \mathrm{TD}}$,

where

$\gamma_{\mathrm{RH}}=\log \left(\frac{b_{\text {ext,high }}}{b_{\text {ext,low }}}\right) / \log \left(\frac{100-\mathrm{RH}_{\text {low }}}{100-\mathrm{RH}_{\text {high }}}\right)$,

and high and low refer to the humidified and dried CRD measurements and again accounting for the sequential nature of the TD and amb measurements. The parameter $\gamma_{\mathrm{RH}}$ can be thought of as the optical hygroscopicity (i.e., a measure of the affinity of particles to take up water and grow), although it does have some dependence on particle size, and thus there is not a one-to-one relationship between $\gamma_{\mathrm{RH}}$ and particle growth (Atkinson et al., 2015). In general, for a given amount of particle growth due to water uptake, $\gamma_{\mathrm{RH}}$ is larger for smaller particles.

The difference in the AAE between the ambient and thermodenuded states can also be determined:

$\Delta \mathrm{AAE}_{\mathrm{amb}-\mathrm{TD}}=\mathrm{AAE}_{\mathrm{amb}}-\mathrm{AAE}_{\mathrm{TD}}$.

Mass absorption, scattering and extinction coefficients (MAC, MSC and MEC, respectively) have been calculated for the various wavelengths and PM size ranges. Using scattering as an example,

$\operatorname{MSC}_{X}\left(\frac{m^{2}}{g}\right)=\frac{b_{\text {sca }}}{[X]}$

where $[X]$ is the mass concentration of the reference species of interest, such as BC or the total PM. In the case of [BC], 


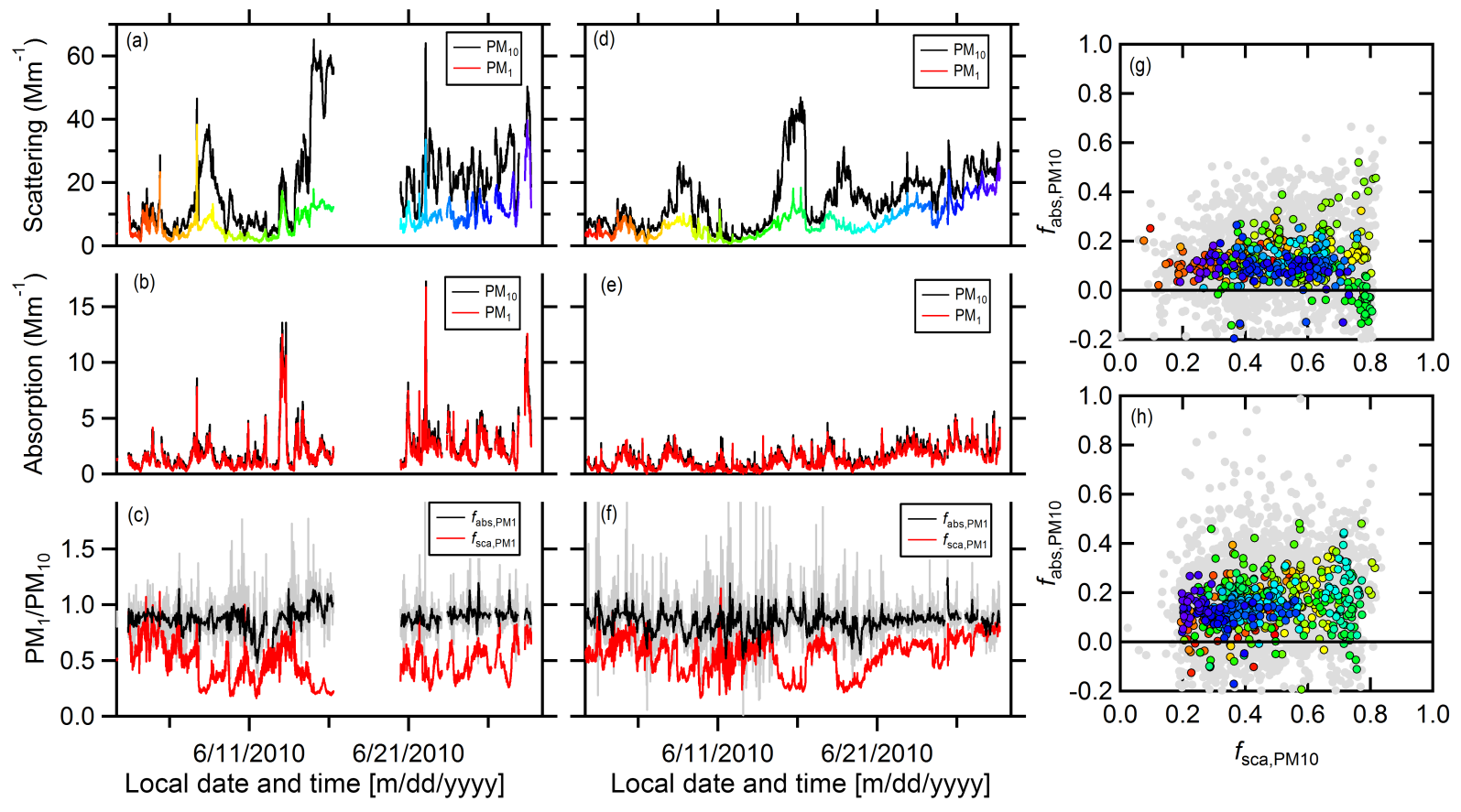

Figure 1. Time series of $\mathrm{PM}_{1}$ and $\mathrm{PM}_{10}$ scattering (a, d) and absorption (b, e) coefficients at $550 \mathrm{~nm}$ for T0 (left panels) and T1 (right panels). Values for $\mathrm{PM}_{10}$ are shown as black lines and for $\mathrm{PM}_{1}$ as colored lines. The ratio between $\mathrm{PM}_{1}$ and $\mathrm{PM}_{10}$ scattering (red) and absorption (black) are shown in (c) and (f). (For absorption, the data have been further averaged to $1 \mathrm{~h}$; the higher time resolution data are shown in gray.) The covariation between $f_{\mathrm{abs}, \mathrm{PM}_{10}}$ and $f_{\mathrm{sca}, \mathrm{PM}_{10}}$ for $\mathrm{T} 0$ (g) and $\mathrm{T} 1$ (h) are also shown. The $1 \mathrm{~h}$ averaged points are colored according to time during the campaign, and correspond to the time series in (a) and (d); the gray points are the data at higher time resolution.

the SP2 measurements are used. For total PM, the integrated volume concentrations were used to estimate [PM], assuming spherical particles. For supermicron particles it was assumed that $\rho_{\mathrm{p}}=2.0 \mathrm{~g} \mathrm{~cm}^{-3}$ and for submicron particles the density was $1.3 \mathrm{~g} \mathrm{~cm}^{-3}$ (Setyan et al., 2012).

The size distributions have been used to calculate median surface-weighted particle diameters $\left(d_{\mathrm{p}, \text { surf }}\right)$ as

$$
d_{\mathrm{p}, \text { surf }}=\frac{\int_{d_{\mathrm{p}, \text { low }}}^{d_{\mathrm{p} \text {,high }}} d_{\mathrm{p}} \cdot \frac{d N}{d \log d_{\mathrm{p}}} d \log d_{\mathrm{p}}}{\int_{d_{\mathrm{p}, \text { low }}}^{d_{\mathrm{p} \text { high }}} \frac{d N}{d \log d_{\mathrm{p}}} d \log d_{\mathrm{p}}},
$$

where $d N / d \log d_{\mathrm{p}}$ is the observed number-weighted size distribution over the size range of interest ( $d_{\mathrm{p} \text {,low }}$ to $\left.d_{\mathrm{p}, \text { high }}\right)$. In this study, $d_{\mathrm{p} \text {,surf }}$ values have been separately calculated for the total $\mathrm{PM}_{10}$ distribution and for the supermicron particle range.

\section{Results and discussion}

\subsection{Size dependence of optical properties}

\subsubsection{Light scattering}

Supermicron particles contributed substantially to the dry particle scattering at both $\mathrm{T} 0$ and $\mathrm{T} 1$ (Fig. 1). The average $f_{\text {sca, } \mathrm{PM}_{1}}(550 \mathrm{~nm})$ at $\mathrm{T} 0$ was $0.48 \pm 0.17(1 \sigma)$ and at $\mathrm{T} 1$ was $0.55 \pm 0.16(1 \sigma)$. (If the time period where the scattering measurements were not available at $\mathrm{T} 0$ is excluded from the $\mathrm{T} 1$ average, the average $f_{\text {sca, } \mathrm{PM}_{1}}$ is $0.57 \pm 0.15(1 \sigma)$.) Thus, nearly $50 \%$ of the dry scattering at these two sites was, on average, due to supermicron particles during the campaign period. This observation is consistent with results from Kassianov et al. (2012), who calculated scattering and direct radiative forcing for these two sites (T0 and T1) based on observed size distributions and concluded that supermicron particles contribute substantially to the total scattering. Because scattering generally increases more rapidly with decreasing wavelength for small particles, the $f_{\mathrm{sca}, \mathrm{PM}_{1}}$ is larger for $450 \mathrm{~nm}$ (i.e., 0.59 at $\mathrm{T} 0$ and 0.67 at $\mathrm{T} 1$ ) and smaller for $700 \mathrm{~nm}$ (i.e., 0.34 at $\mathrm{T} 0$ and 0.41 at T1) compared to $550 \mathrm{~nm}$. The similarity of the $f_{\text {sca, } \mathrm{PM}_{1}}$ values between the two sites is noteworthy given that the T0 site is situated much closer to urban Sacramento than the T1 site is. The $f_{\text {sca, } \mathrm{PM}_{1}}$ values at the two sites show a strong, linear correlation with the 

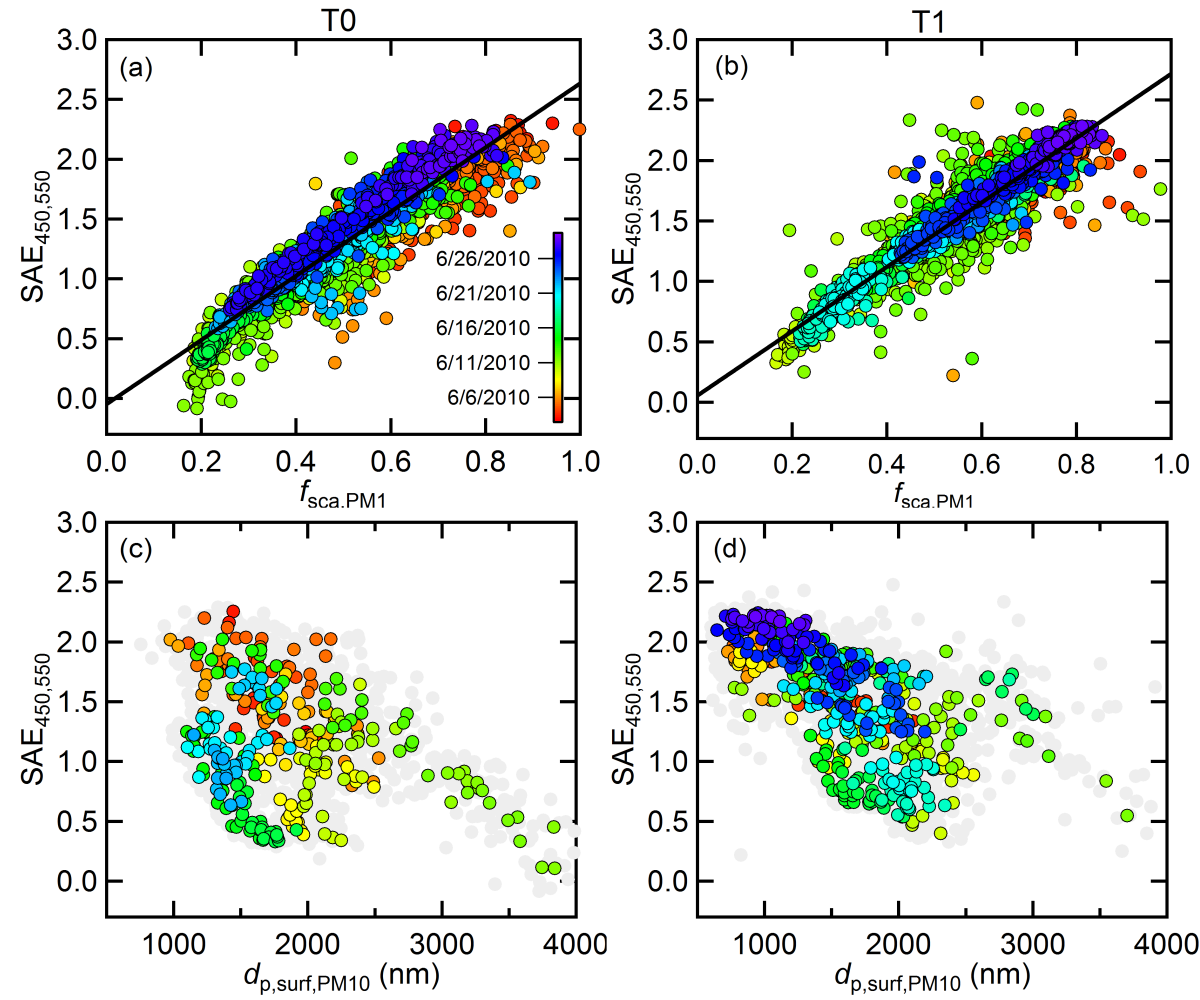

Figure 2. (a, b) The relationship between the $\mathrm{PM}_{10}$ scattering Ångström exponent for the $450-550 \mathrm{~nm}$ pairs and the $f_{\text {sca, }} \mathrm{PM}_{1}$ for both $\mathrm{T} 0$ (left panels) and T1 (right panels). (c, d) The relationship between the SAE and the median surface-weighted diameter for PM 10 . The points in all graphs are colored according to time during the campaign (see legend). For (a, b) data at 10 min resolution are shown, while in (c, d) the colored points are for data averaged to $1 \mathrm{~h}$ and the gray points are for $10 \mathrm{~min}$ data. The fewer colored points in (c) is the result of a malfunction of the APS after 22 June 2010, which precludes calculation of $d_{\mathrm{p}, \mathrm{surf}, \mathrm{PM}_{10}}$.

$\mathrm{SAE}_{450,550, \mathrm{PM}_{10}}$ (Fig. 2a and b), which is not entirely surprising since the SAE provides an indication of the mean, optically weighted particle size. There is a similarly strong relationship with the $\mathrm{SAE}_{\mathrm{PM}_{10}}$ values calculated from the other wavelength pairs (Figs. S4 and S5 show results for the T0 and $\mathrm{T} 1$ sites, respectively, for comparison). The best fit from a one-sided linear fit to $\mathrm{SAE}_{450,550, \mathrm{PM}_{10}}$ versus $f_{\text {sca, } \mathrm{PM}_{1}}$ at T0 is $\mathrm{SAE}_{450,550, \mathrm{PM}_{10}}=2.69 f_{\mathrm{sca}, 550, \mathrm{PM}_{1}-0.05\left(r^{2}=0.88\right) \text { and }}$ at $\mathrm{T} 1$ is $\mathrm{SAE}_{450,550}=2.66 f_{\mathrm{sca}, 550, \mathrm{PM}_{1}}+0.06\left(r^{2}=0.91\right)$. (Values for other combinations of wavelengths for T0 and T1 are reported in Table S2.) Clarke and Kapustin (2010), in a survey of hemispheric aerosol vertical profiles, used a value of $\mathrm{SAE}_{450,550}=1.3$ as a dividing line between air masses impacted by smaller particles from combustion sources $\left(\mathrm{SAE}_{450,550}>1.3\right)$ or coarse-mode particles, such as

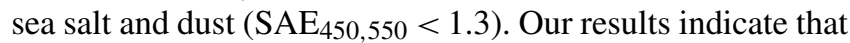
$\mathrm{SAE}_{450,550, \mathrm{PM}_{10}}=1.3$ corresponds to $f_{\text {sca, } 550, \mathrm{PM}_{1}}=0.50$, suggesting that $\mathrm{SAE}_{450,550}=1.3$ is a reasonable dividing line between sub- and supermicron aerosol. They also observed that the relative magnitudes of scattering by smaller versus larger particles was highly variable, depending on altitude and region.
Although the $\mathrm{SAE}_{\mathrm{PM}_{10}}$ values exhibit a linear relationship with $f_{\text {sca, } \mathrm{PM}_{1}}$, they exhibit a more complex relationship with the median surface-area-weighted particle diameter of the entire distribution $\left(d_{\mathrm{p}, \text { surf,PM}} \mathrm{PM}_{10}\right)$. The $\mathrm{SAE}_{\mathrm{PM}_{10}}$ values generally decrease with increasing $d_{\mathrm{p}, \mathrm{surf}, \mathrm{PM}_{10}}$, as one might expect since an increase in $d_{\mathrm{p}, \text { surf, } \mathrm{PM}_{10}}$ presumably corresponds to an increase in the supermicron fraction of scattering. However, there is much greater scatter compared to the clear relationship with $f_{\mathrm{sca}, \mathrm{PM}_{1}}$, and clear periods when a monotonic relationship is not observed (Fig. $2 \mathrm{c}$ and d). The derived $d_{\mathrm{p}, \text { surf, } \mathrm{PM}_{10}}$ values are sensitive to the exact shapes of the sub- and supermicron modes, and the MSC for supermicron particles, in particular, is also sensitive to the shape of the supermicron size distribution (discussed further below in Sect. 3.1.2). Consequently, there is not a straightforward relationship between the $\mathrm{SAE}_{\mathrm{PM}_{10}}$ and $d_{\mathrm{p}, \text { surf, } \mathrm{PM}_{10}}$ and the $\mathrm{SAE}_{\mathrm{PM}_{10}}$ cannot be used to predict average properties of the overall sub- plus supermicron size distribution. However, the strong, linear relationship between the $\mathrm{SAE}_{\mathrm{PM}_{10}}$ and $f_{\text {sca, }} \mathrm{PM}_{1}$ and the close correspondence between the two sites, despite apparent variations in the underlying size distributions, suggests that the relationships derived here may be sufficiently general to be applied in other locations, although this needs 
to be verified. This in turn indicates that observations of $\mathrm{SAE}_{\mathrm{PM}_{10}}$ can be used to quantitatively estimate the fractional contribution of sub- and supermicron particles to the total scattering with an uncertainty of $\sim 15 \%$ based on the spread in the data. Thus, the relationships derived here may be useful for application or comparison with remote sensing methods, such as the AERONET (AErosol RObotic NETwork) sun photometer network (Schuster et al., 2006; Eck et al., 2010) or satellites (Ginoux et al., 2012).

However, a better property to compare with remote sensing methods may be the $\mathrm{PM}_{10}$ extinction Ångström exponent $\left(\mathrm{EAE}_{\mathrm{PM}_{10}}\right.$ ) versus the $\mathrm{PM}_{1}$ extinction fraction, $f_{\text {ext, } \mathrm{PM}_{1}}$. This is complementary to the $\mathrm{SAE}_{\mathrm{PM}_{10}}$ versus $f_{\text {sca, }} \mathrm{PM}_{1}$ relationship discussed above, but focuses on the total optical losses (scattering plus absorption) as opposed to just scattering. The $\mathrm{EAE}_{\mathrm{PM}_{10}}$ and $f_{\text {ext, } \mathrm{PM}_{1}}$ values (for the various wavelength combinations) also exhibit reasonably linear relationships (Fig. S6). The $\mathrm{EAE}_{\mathrm{PM}_{10}}$ value when $f_{\text {ext, } \mathrm{PM}_{1}}=0.5$ is used here as a reference point (referred to here as $\operatorname{EAE}_{\mathrm{PM}_{10}}(0.5)$ ). For a given $\mathrm{EAE}_{\mathrm{PM}_{10}}$ wavelength pair the $\operatorname{EAE}_{\mathrm{PM}_{10}}(0.5)$ increases notably as the wavelength for $f_{\text {ext, } \mathrm{PM}_{1}}$ increases, exhibiting much less sensitivity to the choice of wavelength pair although generally decreasing as the wavelength pairs increase (Table S3). For example, for $\mathrm{EAE}_{450,700, \mathrm{PM}_{10}}$ the $\operatorname{EAE}_{\mathrm{PM}_{10}}(0.5)$ increases from 0.85 to 1.09 to 1.37 for $f_{\text {ext, } \mathrm{PM}_{1}, 450}$ to $f_{\text {ext, } \mathrm{PM}_{1}, 550}$ to $f_{\text {ext, } \mathrm{PM}_{1}, 700 \text {. (Similar behav- }}$ ior is observed for the wavelength sensitivity of the equivalently defined $\operatorname{SAE}_{\mathrm{PM}_{10}}(0.5)$.) The $\mathrm{EAE}_{\mathrm{PM}_{10}}$ versus $f_{\text {ext, }} \mathrm{PM}_{1}$ relationships from these in situ measurements can be compared with remote sensing retrievals of the wavelength dependence of the AOD (i.e., the EAE) and the fine-mode fraction of AOD. The fine-mode fraction of AOD is nominally equivalent to $f_{\text {ext, } \mathrm{PM}_{1}}$ here, and thus they can be directly compared. As one example, Eck et al. (2010) investigated the relationship between the fine-mode fraction of AOD and EAE from AERONET AOD measurements for a few locations around the world. The Eck et al. (2010) observations suggest $\mathrm{EAE}_{440-870, \mathrm{PM}_{10}}(0.5) \sim 0.5$ at $440 \mathrm{~nm}$ and $\mathrm{EAE}_{440-870}(0.5) \sim 0.9$ at $675 \mathrm{~nm}$. These are somewhat smaller than what is observed here, although given the wavelength differences between the in situ and remote sensing measurements, the difference is not unreasonable. Some of the difference in the $\operatorname{EAE}_{\mathrm{PM}_{10}}(0.5)$ values could be attributable to differences in absorption by non-BC species in the regions studied in Eck et al. (2010) (India, China, west Africa) versus in the Sacramento region.

One factor that can influence the sub- versus supermicron contributions to the total scattering is the extent of photochemical processing. Photochemical processing leads to the production of lower volatility material that will tend to condense according to the particle Fuchs-corrected surface area. As such, photochemical processing and secondary PM formation, especially SOA, will lead to preferential growth of the submicron-mode diameters (which grow more for a given amount of condensed material) and will lead to an increase in the submicron scattering in particular. The $f_{\mathrm{sca}, \mathrm{PM}_{1}}$ at T0 exhibits a general increase with PCA (characterized by the $\left[\mathrm{NO}_{x}\right] /\left[\mathrm{NO}_{y}\right]$ and/or [benzene]/[toluene] ratios), although there is a fair amount of scatter at low photochemical age (Fig. $3 \mathrm{a}$ and b). The $f_{\text {sca, } \mathrm{PM}_{1}}$ at T1 shows completely different behavior, with $f_{\text {sca, } \mathrm{PM}_{1}}$ exhibiting very little dependence on PCA, although there is possibly a slight decrease (Fig. 3c). There is generally good correspondence between the $\left[\mathrm{NO}_{x}\right] /\left[\mathrm{NO}_{y}\right]$ and [benzene]/[toluene] ratios measured at $\mathrm{T} 0$, indicating that the different results at $\mathrm{T} 1$ are unlikely to result from use of a particular PCA marker (Fig. 3d). The PCA at T1 is on average much larger than at T0. The PCA at the T0 site exhibits a clear peak around 15:00 PDT (Fig. 3e). The PCA diel profile at T1 is comparably much broader and exhibits a less pronounced peak, but that also occurs in the late afternoon (around 16:00 PDT) (Fig. 3e). This broadening and different temporal dependence likely reflects the downwind location of the $\mathrm{T} 1$ site and the general flow patterns in this region (Fast et al., 2012). It seems likely that the difference in variation of the $f_{\mathrm{sca}, \mathrm{PM}_{1}}$ with PCA between the two sites is related to this difference. At T0, the measured $b_{\text {sca,PM }}$ may reflect a relatively local production of submicron particulate mass whereas at $\mathrm{T} 1$ the $b_{\mathrm{sca}, \mathrm{PM}_{1}}$ is more reflective of regional conditions. The $b_{\text {sca,super }}$ at both sites will have some regional contribution (in particular sea spray), but also a strong local contribution. Wind speeds were typically largest in the mid-afternoon to late afternoon at both sites, although overall the diel behavior was much clearer at T1 than at T0 and with a larger amplitude (Fig. 3e). However, the wind speeds were on average larger at T0. Thus, it seems reasonable to conclude that local emission of supermicron particulates, possibly resuspended road dust or from agricultural sources, in the afternoon at $\mathrm{T} 1$ counteracts the influence of growth of the regional submicron particulates, leading $f_{\text {sca, }} \mathrm{PM}_{1}$ to be nearly independent of PCA at this site. In contrast, at T0 the local photochemical production of new submicron PM mass appears to be sufficiently strong to lead to an increase in $f_{\text {sca, } \mathrm{PM}_{1}}$ with PCA.

The relationship between the $\mathrm{PM}_{10}$ SSA and the $\mathrm{PM}_{1}$ extinction fraction $\left(f_{\text {ext, } \mathrm{PM}_{1}}\right)$ can also be examined to understand how the extent of scattering versus absorption relates to particle size (Fig. 4). At T0, the $\mathrm{SSA}_{\mathrm{PM}_{10}}$ at all three wavelengths decreases as $f_{\text {ext, } \mathrm{PM}_{1}, 700 \text { increases for }}$

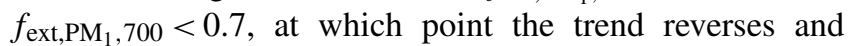

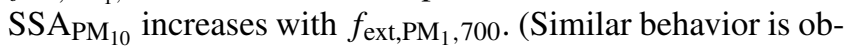
served when $f_{\text {ext, }} \mathrm{PM}_{10}$ values at the other wavelengths are used. The choice of $700 \mathrm{~nm}$ was made to facilitate comparison with AERONET observations, below.) At T1, the relationship is somewhat different, with $\mathrm{SSA}_{\mathrm{PM}_{10}}$ decreasing with $f_{\text {ext }, \mathrm{PM}_{1}, 700}$ until about $f_{\text {ext, } \mathrm{PM}_{1}, 700}=0.55$, above which the SSA is relatively constant. The decrease in $\mathrm{SSA}_{\mathrm{PM}_{10}}$ with $f_{\text {ext, } \mathrm{PM}_{1}}$ below some value can be understood as resulting from an increasing contribution of absorbing black carbon as $\mathrm{PM}_{1}$ comes to dominate the extinction, and limited absorption by the supermicron particles at all wavelengths. 

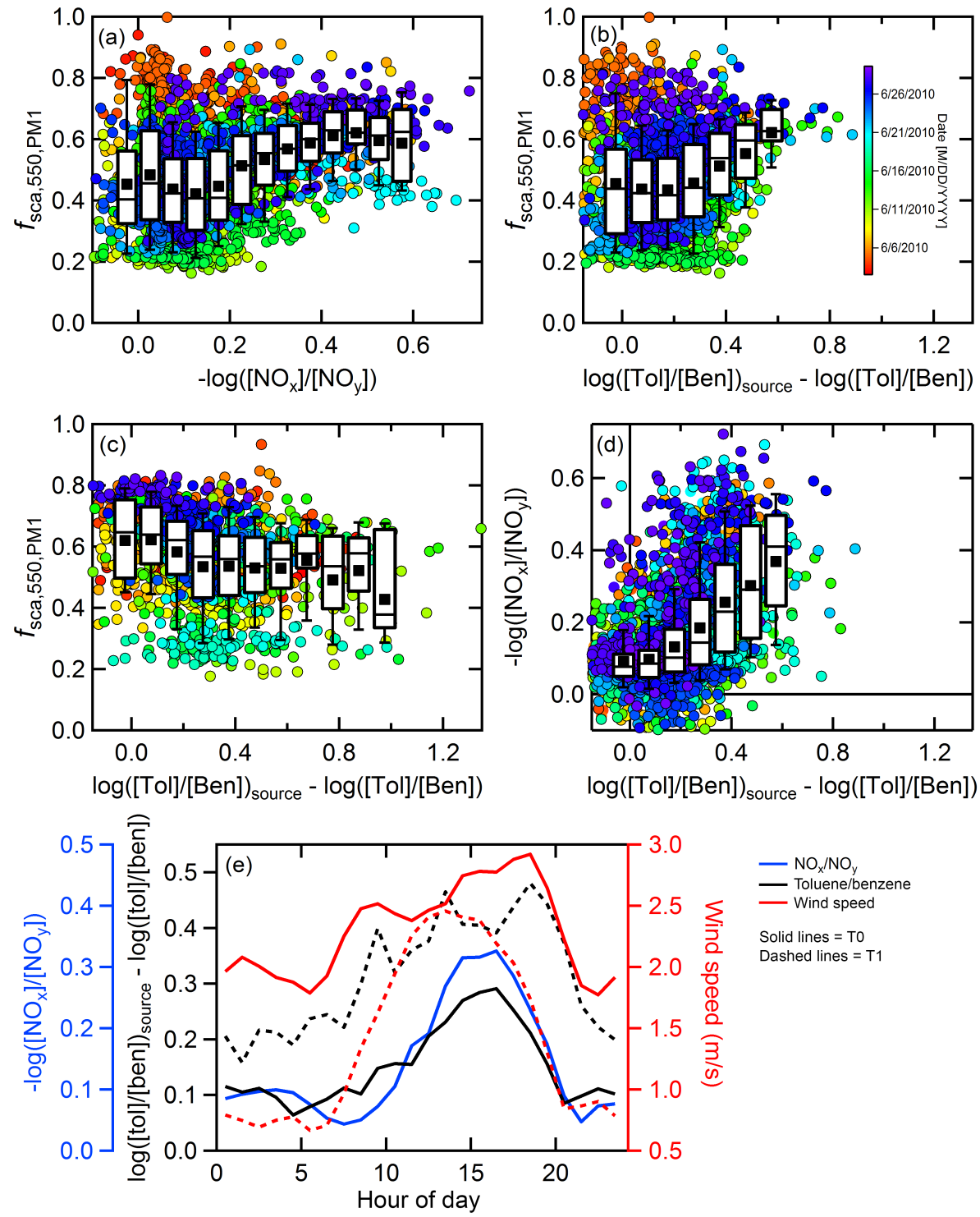

Figure 3. Submicron fraction of scattering for the $\mathrm{T} 0$ and $\mathrm{T} 1$ sites as a function of photochemical age proxies. Observations at $\mathrm{T} 0$ using the (a) $\mathrm{NO}_{x} / \mathrm{NO}_{y}$ ratio and the (b) toluene / benzene ratio and at $\mathrm{T} 1$ for the (c) toluene / benzene ratio as the PCA proxy. Individual measurements (averaged to $10 \mathrm{~min}$ ) are colored by time. (d) The relationship between the two PCA estimation methods at T0. (e) The diurnal variation in the PCA estimation methods and the measured wind speed for T0 (solid lines) and T1 (dashed lines). Box and whisker plots show the median (line), mean (square) upper and lower quartile (box) and 10th and 90th percentile (whiskers).

The increase at $\mathrm{T} 0$ above $f_{\mathrm{ext}, \mathrm{PM}}, 700=0.7$ can be understood as an increase in the contribution of local, photochemical production of secondary inorganic and organic aerosol within the submicron size range. At $\mathrm{T} 1$, the flat relationship above $f_{\text {ext,PM }, 700}=0.55$ likely results from a dampening of the local BC impact as air masses travel from T0 to T1. When $f_{\text {ext,PM}}, 700$ is small (supermicron-dominated) the $\mathrm{SSA}_{\mathrm{PM}_{10}}$ increases very slightly with wavelength (i.e., $\mathrm{SSA}_{\mathrm{PM}_{10}, 700}>\mathrm{SSA}_{\mathrm{PM}_{10}, 450}$ ), but as $f_{\text {ext, } \mathrm{PM}_{1}, 700}$ increases the trend is reversed and the differences between wavelengths become larger. This demonstrates that the SSA versus wave- length relationship is fundamentally different between the sub- and supermicron particles in this region.

These relationships can also be compared with results from remote sensing. As above, we consider as an example measurements from AERONET (Eck et al., 2010). (Note that SSA data from AERONET retrievals are limited to periods when the AOD is $>0.4$ at $440 \mathrm{~nm}$, which is generally during high-concentration periods (Dubovik and King, 2000). AERONET AOD measurements (http://aeronet.gsfc. nasa.gov/) are available from the nearby McClellan Air Force Base from 8 to 12 June 2010, overlapping the CARES study 

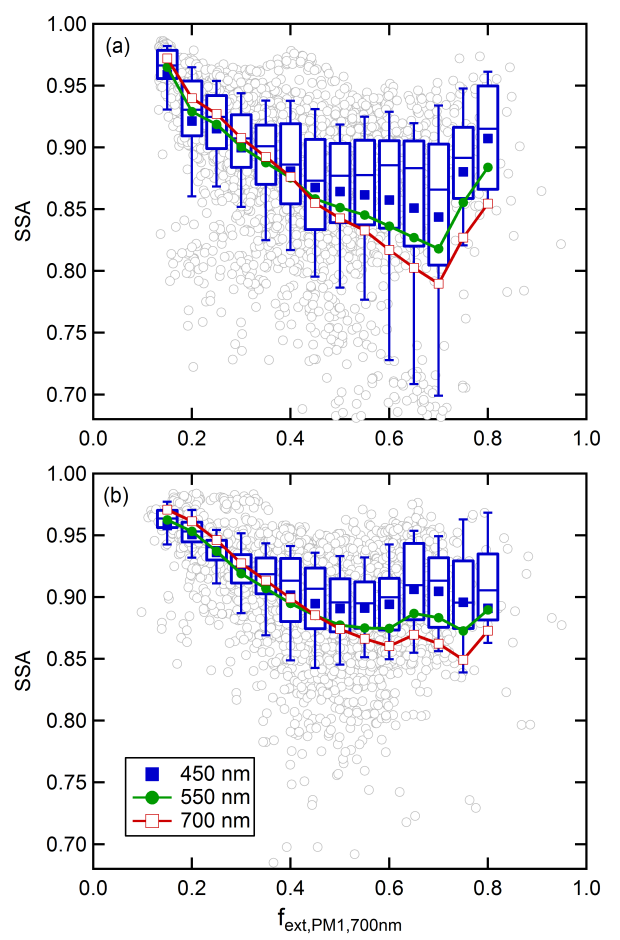

Figure 4. Relationship between the $\mathrm{PM}_{10}$ SSA and the $\mathrm{PM}_{1}$ frac-

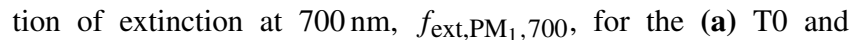
(b) $\mathrm{T} 1$ sites. The individual data points (gray circles) are shown for the $\mathrm{SSAPM}_{10}$ at $450 \mathrm{~nm}$ along with a box-and-whisker plot binned by $f_{\text {ext, }} \mathrm{PM}_{1}, 700$. For the $\mathrm{SSA}_{\mathrm{PM}_{10}}$ at $550 \mathrm{~nm}$ (green line) and $700 \mathrm{~nm}$ (red line) only the mean, binned values are shown.

period. During these days, the maximum $\mathrm{AOD}_{440 \mathrm{~nm}}$ (for Level 2 data) was $\sim 0.20$, below the SSA retrieval threshold. Thus, we cannot compare our in situ measurements directly to AERONET measurements from the same location and time period.) The shape of the observed $\mathrm{SSA}_{\mathrm{PM}_{10}}$ versus $f_{\text {ext, } \mathrm{PM}_{1}, 700}$ curves at $\mathrm{T} 0$ are quite similar to that observed by AERONET for $\mathrm{SSA}_{675}$ versus the fine-mode fraction of AOD at $675 \mathrm{~nm}$ over India (Kanpur) and China (Beijing). However, the $\mathrm{SSA}_{440}$ versus fine-mode fraction of AOD at $675 \mathrm{~nm}$ curves from AERONET over these same locations was much flatter than observed here for $\mathrm{SSA}_{\mathrm{PM}_{10}, 450 \text { versus }}$

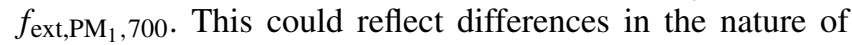
the supermicron particles between these regions and Sacramento, with apparently higher absorption by supermicron particles at shorter wavelengths in India and China leading to a weaker dependence of $\mathrm{SSA}_{440}$ on particle size than observed here.

\subsubsection{Light absorption}

Light absorption at both sites was dominated by submicron particles, although a small fraction may also be from supermicron particles (Fig. 1). The average $f_{\mathrm{abs}, \mathrm{PM}_{1}}$ at $532 \mathrm{~nm}$ at T0 was $0.89 \pm 0.14(1 \sigma)$ and at $\mathrm{T} 1$ was $0.85 \pm 0.17(1 \sigma)$.
At $\mathrm{T} 1$ there is a slight indication that $f_{\text {abs,super }}$ decreased as $f_{\text {sca,super }}$ decreased, but no such relationship is clearly evident at T0 (Fig. 1g and h). Such potential relationships must be viewed with some amount of caution, as the PSAP requires correction for particle scattering and the extent of forward versus backward scattering is particle-size-dependent. It is also known that the PSAP shows an additional sensitivity to particle size due to differences in the depth of penetration of particles into the filter (Nakayama et al., 2010), which might influence the measurements here.

The fact that light absorption is dominated by submicron particles suggests that black carbon, and possibly brown carbon, make up the majority of the light-absorbing particle burden. The $\mathrm{AAE}_{\mathrm{PM}_{1}}$ values at both $\mathrm{T} 0$ and $\mathrm{T} 1$ exhibit reasonably normal distributions (Fig. 5). The spread at T0 was substantially smaller than at $\mathrm{T} 1$. The average $\mathrm{AAE}_{\mathrm{PM}_{1}}$ values are slightly larger than unity at both sites $(1.21 \pm 0.13$ and $1.33 \pm 0.22$ for $\mathrm{T} 0$ and $\mathrm{T} 1$, respectively, where uncertainties are 1 SD (standard deviation); Table 2), and do not show any pronounced dependence on the wavelength pair chosen. Black carbon is typically thought to have an AAE close to unity (Cross et al., 2010). The average $\mathrm{PM}_{1} \mathrm{AAE}_{\mathrm{PM}_{1}, 450-532}$ are identical between the sites, whereas the $\mathrm{AAE}_{\mathrm{PM}_{1}, 450-660}$ and $\mathrm{AAE}_{\mathrm{PM}_{1}, 532-660}$ are slightly larger at $\mathrm{T} 1$. The larger spread in the $\mathrm{AAE}_{\mathrm{PM}_{1}}$ values for all wavelength pairs at $\mathrm{T} 1$ suggests that the two PSAP instruments were not entirely identical and had somewhat different noise characteristics, making it difficult to establish whether these small differences are real. One method that has been used to estimate the contribution of brown carbon relative to black carbon is to extrapolate the observed $b_{\mathrm{abs}}$ at longer $\lambda$ (e.g., $660 \mathrm{~nm}$ ) to shorter wavelengths, assuming that AAE is 1 and that absorption by brown carbon at long $\lambda$ is zero (Gyawali et al., 2009; Yang et al., 2009; Chung et al., 2012; Lack and Langridge, 2013). To the extent that this method is appropriate, and some have argued it may not be (Lack and Langridge, 2013), it provides an estimate of $b_{\text {abs }}$ for pure $\mathrm{BC}$ (assuming that $\mathrm{AAE}_{\mathrm{BC}}=1$ exactly) and the contribution from brown carbon can then be estimated by subtracting the pure $\mathrm{BC} b_{\mathrm{abs}}$ from the total. Given the observed $\mathrm{AAE}_{\mathrm{PM}_{1}}$ values, this spectral differencing method suggests that brown carbon contributes $\sim 6 \%$ at $\mathrm{T} 0$ and up to $11 \%$ at $\mathrm{T} 1$ to submicron particle light absorption at $450 \mathrm{~nm}$; if the actual $\mathrm{AAE}_{\mathrm{BC}}$ were $>1$, as possibly suggested by the $\mathrm{AAE}_{532-660}$ measurements at both sites, then the attributed brown carbon fraction would be even smaller and canceled out entirely if $\mathrm{AAE}_{\mathrm{BC}}$ equals the observed value for the ambient particles. These relatively minor contributions from brown carbon are consistent with the conclusions of Cappa et al. (2012) and indicate that in this region the summertime submicron particulate light absorption is predominately from black carbon.

There are two likely origins of the supermicron absorption (assuming it is not simply an artifact): penetration of $\mathrm{BC}$ into the supermicron size range, likely from coagulation of $\mathrm{BC}$ with larger particles or tailing of the pre- 
Table 2. Campaign average optical properties at $\mathrm{T} 0$ and $\mathrm{T} 1$ for submicron and supermicron particles.

\begin{tabular}{|c|c|c|c|c|c|}
\hline \multirow[b]{2}{*}{ Property } & \multicolumn{3}{|c|}{ T0 } & \multicolumn{2}{|c|}{$\mathrm{T} 1$} \\
\hline & $\mathrm{PM}_{1}$ & $\mathrm{PM}_{2.5}$ & Supermicron $^{\mathrm{a}}$ & $\mathrm{PM}_{1}$ & Supermicron $^{\mathrm{a}}$ \\
\hline$b_{\mathrm{sca}, 450}$ & $12.9 \mathrm{Mm}^{-1}$ & & $10.7 \mathrm{Mm}^{-1}$ & $12.7 \mathrm{Mm}^{-1}$ & $6.6 \mathrm{Mm}^{-1}$ \\
\hline$b_{\text {sca, } 550}$ & $7.9 \mathrm{Mm}^{-1}$ & & $10.9 \mathrm{Mm}^{-1}$ & $7.6 \mathrm{Mm}^{-1}$ & $6.8 \mathrm{Mm}^{-1}$ \\
\hline$b_{\text {sca, } 700}$ & $4.2 \mathrm{Mm}^{-1}$ & & $10.9 \mathrm{Mm}^{-1}$ & $3.4 \mathrm{Mm}^{-1}$ & $6.8 \mathrm{Mm}^{-1}$ \\
\hline$b_{\mathrm{abs}, 470}$ & $2.3 \mathrm{Mm}^{-1}$ & & $0.31 \mathrm{Mm}^{-1}$ & $1.45 \mathrm{Mm}^{-1}$ & $0.26 \mathrm{Mm}^{-1}$ \\
\hline$b_{\mathrm{abs}, 530}$ & $1.9 \mathrm{Mm}^{-1}$ & & $0.25 \mathrm{Mm}^{-1}$ & $1.25 \mathrm{Mm}^{-1}$ & $0.20 \mathrm{Mm}^{-1}$ \\
\hline$b_{\mathrm{abs}, 660}$ & $1.5 \mathrm{Mm}^{-1}$ & & $0.19 \mathrm{Mm}^{-1}$ & $0.95 \mathrm{Mm}^{-1}$ & $0.14 \mathrm{Mm}^{-1}$ \\
\hline$b_{\text {ext }, 405}$ & & $27.0 \mathrm{Mm}^{-1}$ & & & \\
\hline$b_{\mathrm{ext}, 532}$ & & $18.0 \mathrm{Mm}^{-1}$ & & & \\
\hline$b_{\mathrm{abs}, 405}$ & & $2.8 \mathrm{Mm}^{-1}$ & & & \\
\hline$b_{\mathrm{abs}, 532}$ & & $2.1 \mathrm{Mm}^{-1}$ & & & \\
\hline $\mathrm{AAE}_{470-532}^{\mathrm{b}}$ & $1.21 \pm 0.18$ & & $1.93 \pm 0.83$ & $1.22 \pm 0.33$ & $2.03 \pm 1.04$ \\
\hline $\mathrm{AAE}_{470-660}^{\mathrm{b}}$ & $1.17 \pm 0.11$ & & $1.54 \pm 0.50$ & $1.28 \pm 0.22$ & $1.76 \pm 0.69$ \\
\hline $\mathrm{AAE}_{532-660}^{\mathrm{b}}$ & $1.15 \pm 0.12$ & & $1.30 \pm 0.52$ & $1.28 \pm 0.21$ & $1.68 \pm 0.77$ \\
\hline $\mathrm{AAE}_{405-532}^{\mathrm{b}^{32-660}}$ & & $1.3 \pm 0.9$ & & & \\
\hline $\mathrm{SAE}_{450-550}^{\mathrm{c}^{\mathrm{C}}}$ & $2.42 \pm 0.38$ & & $-0.13 \pm 0.31$ & $2.58 \pm 0.27$ & $-0.15 \pm 0.34$ \\
\hline EAE $_{405-532}^{\mathrm{c}^{\mathrm{c}}}$ & & $1.53 \pm 0.5$ & & & \\
\hline
\end{tabular}

a Values for supermicron particles are calculated as the difference between $\mathrm{PM}_{10}$ and $\mathrm{PM}_{1}$. ${ }^{\mathrm{b}}$ The reported uncertainties were determined from fitting a histogram of the observed values to a Gaussian distribution and are the $1 \sigma$ spread. ${ }^{\mathrm{c}}$ The reported uncertainties are $1 \sigma$ standard deviations.
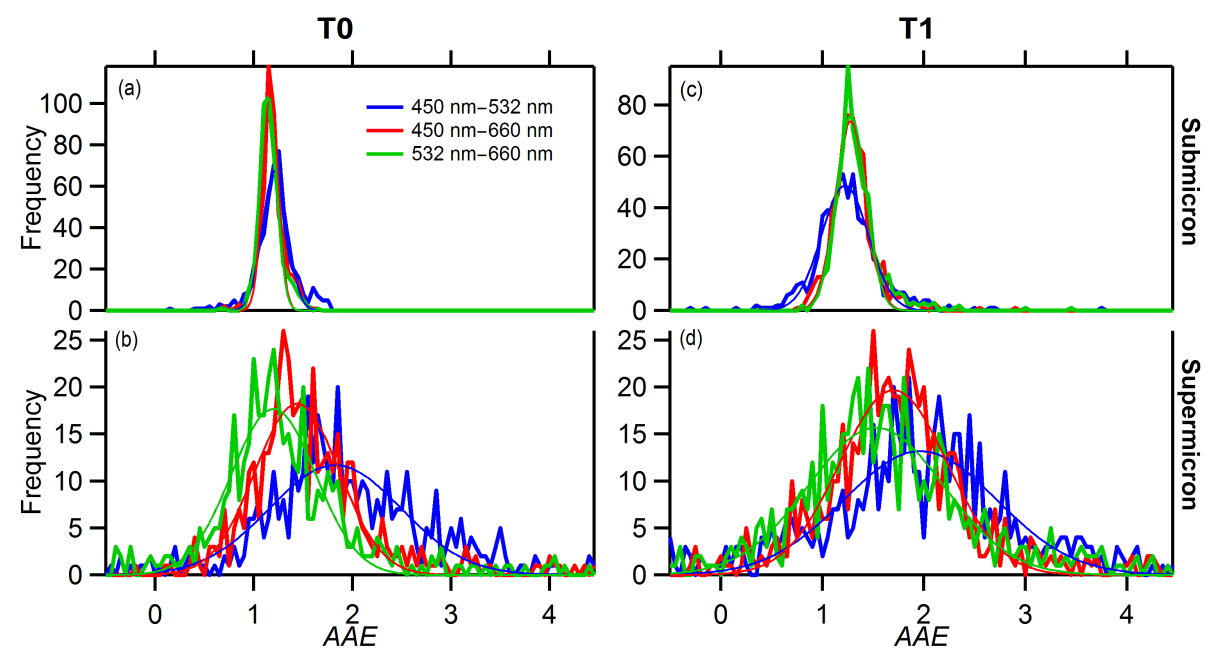

Figure 5. Histograms of the measured AAE values for various wavelength pairs for submicron (top; a and c) and supermicron (bottom; b and d) particles at the T0 (left panels) and T1 (right panels) sites. The different colors correspond to different wavelength pairs (see legend). The thick lines correspond to the observations while the thin lines show the results from fitting of the distributions to a Gaussian function.

dominately submicron BC size distribution, or dust (assuming the observed supermicron absorption is not simply an experimental artifact). Dust is known to contribute substantially to the $\mathrm{PM}_{10}$ burden in Sacramento, with sources including local emissions from roadways, agricultural activity and disturbed open residential areas (California Air Resources Board, 2005; http://www.arb.ca.gov/pm/ pmmeasures/pmch05/pmch05.htm), and long-range transport (Ewing et al., 2010). The single particle measurements from the SPLAT-II instrument at T0 indicate that both BCcontaining and dust particles are observed in the supermicron size range, along with substantial contributions from sea-salt-containing particles that are likely of marine origin (Fig. S7). The PALMS instrument detected similar particle types at the T1 site (Zaveri et al., 2012). Although informative, these measurements unfortunately cannot be used to quantitatively assess the relative contributions of the different absorbing particle types to the supermicron absorption 
because both instruments sample only over a subset of the entire supermicron size range, e.g., the SPLAT-II only samples up to $d_{\mathrm{v}, \mathrm{a}} \sim 2 \mu \mathrm{m}$, and matrix effects can impact quantification of individual components in mixed particles (e.g., BC mixed with dust). Nonetheless, the single particle composition measurements provide support for both the likely origins of the supermicron absorption being from either BC penetration or dust.

Dust and BC should be distinguishable based on the observed spectral properties and chemical composition. Although the optical properties of dust vary by location and source, dust is generally thought to have AAE values $>1$, with typical reported values of $\sim 1.5-3$ (Yang et al., 2009; Russell et al., 2010; Bahadur et al., 2012), larger than is typically observed for black carbon. The measured average $\mathrm{AAE}_{\text {super }}$ values were greater than unity and larger than the $\mathrm{AAE}_{\mathrm{PM}_{1}}$ (Table 2), suggestive of a dust influence. However, there are two important points to consider. First, although the $\mathrm{AAE}_{\text {super }}$ values were approximately normally distributed, the distributions were substantially broader than the distributions for the submicron particles, with a range of about $0.5<\mathrm{AAE}_{\text {super }}<3$ (Fig. 5). Second, the $\mathrm{AAE}_{\text {super val- }}$ ues exhibited a notable wavelength-pair dependence, with the largest values observed for the $450-532 \mathrm{~nm}$ pair and the smallest for the 532-660 nm pair and where the wavelength dependence at T0 was much larger than at T1 (Table 2; Fig. 5). The large spread in the $\mathrm{AAE}_{\text {super }}$ values may reflect the small magnitudes of the absolute $b_{\text {abs,super val- }}$ ues and the use of the difference method to determine the $b_{\text {abs,super }}$ (i.e., noise), but could also indicate a greater diversity in $\mathrm{AAE}_{\text {super }}$ values compared to $\mathrm{AAE}_{\mathrm{PM}_{1}}$ due to, perhaps, time-varying contributions from dust and $\mathrm{BC}$. As a test, if the averaged $\mathrm{AAE}_{\mathrm{PM}_{1}}$ values are restricted to periods when the absolute absorption was relatively low $\left(<0.6 \mathrm{Mm}^{-1}\right)$, but still generally larger than the $b_{\mathrm{abs}, \text { super }}$, there is no substantial additional broadening of the distribution. This suggests that the broadening of $\mathrm{AAE}_{\text {super }}$ may be real and that the latter interpretation - diversity in individual $\mathrm{AAE}_{\text {super }}$ values - may be appropriate. However, since there were insufficient periods where the $b_{\mathrm{abs}, \mathrm{PM}_{1}}$ values were as low as the $b_{\text {abs,super, }}$, changes in the shape of the $\mathrm{AAE}_{\mathrm{PM}_{1}}$ distribution cannot be assessed under the exact same conditions, and thus the possibility that the greater scatter simply reflects the low

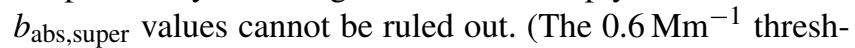
old was chosen to allow for a sufficient number of $\mathrm{AAE}_{\mathrm{PM}_{1}}$ values to remain to be used to develop a histogram.) Also, if one considers the relationship between $\mathrm{AAE}_{\mathrm{PM}_{10}}$ and the $f_{\text {sca, } \mathrm{PM}_{1}}$, there is no obvious broadening of the AAE distribution at smaller values of $f_{\mathrm{sca}, \mathrm{PM}_{1}}$. There is also some indication of correlations between both $b_{\mathrm{abs}, \text { super }}$ and $b_{\mathrm{abs}, \mathrm{PM}_{1}}$ and between $b_{\text {abs,super }}$ and [BC] (as measured by the SP2) (Fig. 6). Although the correlation coefficients are relatively small ( $r^{2}=0.45$ and 0.25 at $\mathrm{T} 0$ and $\mathrm{T} 1$, respectively), this could indicate contributions from penetration of $\mathrm{BC}$ into the supermicron mode, which could help to explain why most of
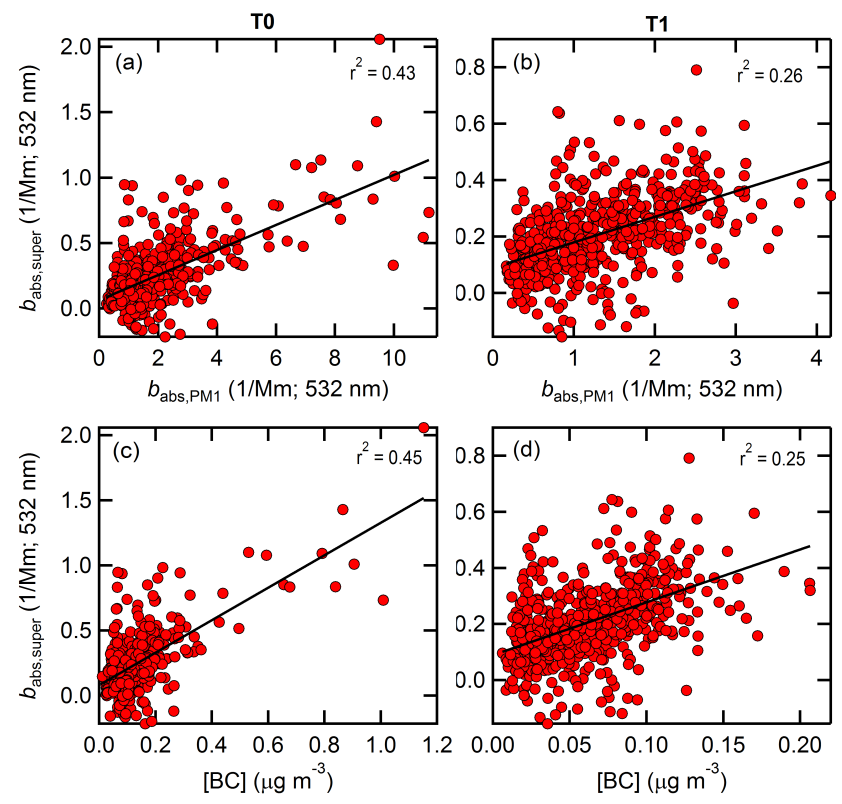

Figure 6. Covariation of the supermicron absorption at T0 (left panels) and T1 (right panels) with the submicron absorption (top panels) and with black carbon concentration (bottom panels). Note that negative values of $b_{\text {abs,super }}$ result from this being derived from the difference between $b_{\mathrm{abs}, \mathrm{PM}_{10}}$ and $b_{\mathrm{abs}, \mathrm{PM}_{1}}$.

the $\mathrm{AAE}_{\text {super }}$ values are smaller than is typical for pure dust but larger than for $\mathrm{BC}$.

Further insight into the nature of the supermicron particles comes from consideration of the MAC and MSC values, which are intensive properties like the AAE. The MAC and MSC for supermicron particles have been assessed by comparing $b_{\text {abs,super }}$ and $b_{\text {sca,super }}$ with the supermicron mass concentration ( $\left.\left[\mathrm{PM}_{\text {super }}\right]\right)$ as estimated from the measured size distributions (Fig. $7 \mathrm{a}$ and $\mathrm{b}$ ). The $\left[\mathrm{PM}_{\text {super }}\right]$ values were estimated assuming a density of $2 \mathrm{~g} \mathrm{~cm}^{-3}$ and spherical particles. In theory, the MSC is size-dependent, falling off rapidly from $\sim 4 \mathrm{~m}^{2} \mathrm{~g}^{-1}$ to $\sim 1.5 \mathrm{~m}^{2} \mathrm{~g}^{-1}$ in going from $d_{\mathrm{p}, \mathrm{m}}=700$ to $1000 \mathrm{~nm}$ (with $d_{\mathrm{p}, \mathrm{m}}=700 \mathrm{~nm}$ corresponding approximately to $d_{\mathrm{p}, \mathrm{a}}=1000 \mathrm{~nm}$ when density $=2 \mathrm{~g} \mathrm{~cm}^{-3}$ ) and ranging from $\sim 0.5$ to $1.5 \mathrm{~m}^{2} \mathrm{~g}^{-1}$ for larger particles (see Fig. S8 and Clarke et al., 2004). Thus, smaller MSC values generally correspond to larger particles. The observed $\mathrm{MSC}_{\text {super }}$ exhibit an inverse relationship with $d_{\mathrm{p} \text {,surf }}$ for the supermicron particles (Fig. 7e and f). To our knowledge, this is the first explicit demonstration of the theoretically expected inverse relationship from ambient observations. These observations indicate that the nature of the supermicron particle size distributions do vary with time, with some time periods containing larger supermicron particles and some smaller. This variability in size suggests variations in the supermicron particle sources, and consequently in the chemical nature of the particles, discussed further below. 

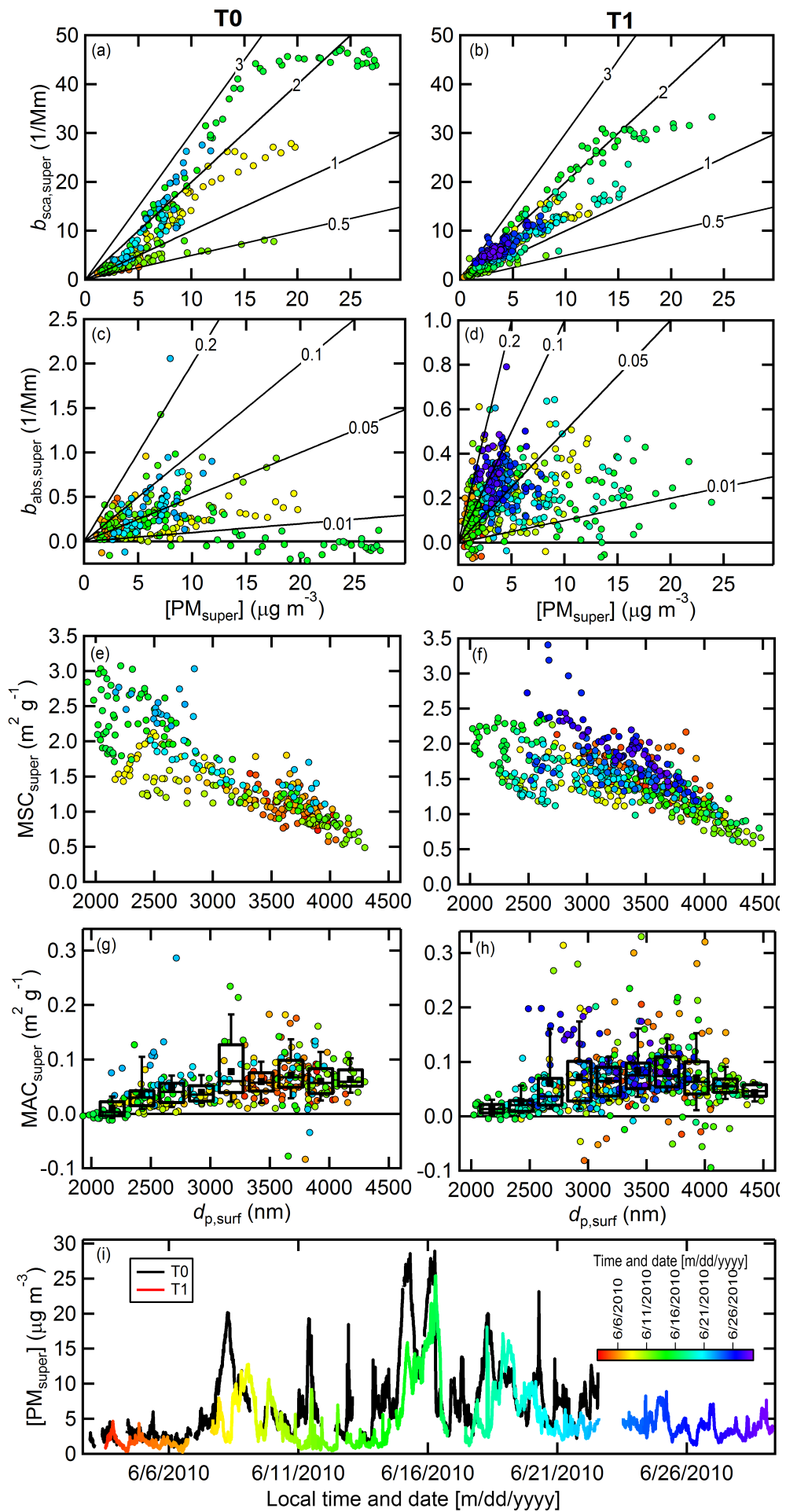

Figure 7. (a, b) Scatter plot between $b_{\text {sca,super }}$ at $532 \mathrm{~nm}$ and $\left[\mathrm{PM}_{\text {super }}\right]$ for (left panels) T0 and (right panels) T1. The lines correspond to different MSC values (in $\mathrm{m}^{2} \mathrm{~g}^{-1}$ ). (c, d) Scatter plot between $b_{\text {abs,super }}$ at $532 \mathrm{~nm}$ and $\left[\mathrm{PM}_{\text {super }}\right.$. The lines correspond to different MAC values (in $\mathrm{m}^{2} \mathrm{~g}^{-1}$ ). (e, f) The relationship between $1 \mathrm{~h}$ average MSC values and the surface-area-weighted mean diameter, $d_{\mathrm{p} \text {,surf }}$ at the two sites. $(\mathbf{g}, \mathbf{h})$ The relationship between $1 \mathrm{~h}$ average MAC values and $d_{\mathrm{p} \text {,surf }}$ at the two sites. The individual $1 \mathrm{~h}$ average data points are shown overlaid by box-and-whisker plots showing the mean (), median (-), lower and upper quartile (boxes), and 9th and 91st percentile (whiskers). The points in (a)-(h) are colored according to time, and correspond to the colors in the bottom figure and color scale. (i) Time series of the supermicron particle mass concentration for T0 and T1. T0 values are black lines, and T1 values are colored according to time. 
The relationship between $b_{\text {abs,super }}$ and $\left[\mathrm{PM}_{\text {super }}\right]$ exhibits a great deal of scatter (Fig. 7c and d), most likely due to the small values of $b_{\text {abs,super }}$ and to the variability in the $\mathrm{PM}_{\text {super }}$ sources, including particle density and size. The MAC values at $532 \mathrm{~nm}$ for the supermicron particles range from $\sim 0$ to $\sim 0.06 \mathrm{~m}^{2} \mathrm{~g}^{-1}$ at both sites. Further, the MAC ${ }_{\text {super }}$ values exhibit a notable dependence on the $d_{\mathrm{p} \text {,surf }}$ (Fig. $7 \mathrm{~g}$ and $\mathrm{h}$ ). In general, when $d_{\mathrm{p} \text {,surf }}$ is on the small side $(\sim 2 \mu \mathrm{m})$ the $\mathrm{MAC}_{\text {super }}$ is very close to zero and it tends to increase with $d_{\mathrm{p} \text {,surf }}$. Apparently, the particles from sources that produced, on average, smaller supermicron particles were less absorbing than the particles from sources that produced larger particles. A plausible explanation is that the larger particles are dust while the smaller (yet still supermicron) particles are a combination of non-absorbing sea spray particles and other particle types that are penetrating from the submicron mode. This hypothesis is generally supported by examination of HYSPLIT (HYbrid Single-Particle Lagrangian Integrated Trajectory model) back trajectories (Draxler and Rolph, 2015) for each day of the campaign (Fig. S9), as well as by comparison with the source-region identification in Fast et al. (2012), with smaller $d_{\mathrm{p} \text {,surf }}$ values for the supermicron particles generally corresponding to periods when the air masses were identified as containing a greater Bay Area contribution. Considering three specific days as examples, two (11 and 16 June) when the $\mathrm{MSC}_{\text {super }}$ were particularly small (corresponding to larger particles) and one (15 June) when the $\mathrm{MSC}_{\text {super }}$ were larger, clear differences in the air mass origins can be seen. Specifically, the back trajectories on 11 and 16 June indicate that the air mass came from almost due north, consistent with a terrestrial origin for the particles while the back trajectory on 15 June indicates that the air mass had passed over the San Francisco Bay Area and before that came from along the CA coast. These back trajectories are generally consistent with the idea that when the overall size distribution is skewed towards smaller supermicron particles (smaller $d_{\mathrm{p} \text {,surf }}$ and larger $\mathrm{MSC}_{\text {super }}$ ) the air masses are more impacted by sea spray particles, while when the size distribution is skewed towards larger particles there is a greater relative dust contribution.

Even though the $\mathrm{MAC}_{\text {super }}$ exhibits a pronounced relationship with $d_{\mathrm{p} \text { surf }}$, there is actually minimal dependence of $b_{\text {abs,super }}$ on $d_{\mathrm{p} \text {,surf }}$ (Fig. S10). There is, however, a relatively strong relationship between $\left[\mathrm{PM}_{\text {super }}\right]$ and $d_{\mathrm{p} \text {,surf }}$, with larger [ $\left[\mathrm{PM}_{\text {super }}\right]$ usually corresponding to smaller $d_{\mathrm{p} \text {,surf }}$ (Fig. S10). This suggests that the small $\mathrm{MAC}_{\text {super values at }}$ small $d_{\text {p,surf }}$ result from substantial inputs of non-absorbing supermicron particles, which does not necessarily alter the observed $b_{\text {abs,super }}$ but does serve to increase the $\left[\mathrm{PM}_{\text {super }}\right]$, thereby depressing the $\mathrm{MAC}_{\text {super values. The }} \mathrm{MAC}_{\text {super }}$ is approximately $0.06 \mathrm{~m}^{2} \mathrm{~g}^{-1}$ when $d_{\mathrm{p} \text {,surf }}$ is large (i.e., $>3.5 \mu \mathrm{m}$; Fig. 7). If it is assumed that the major contributor to supermicron absorption when $d_{\mathrm{p} \text {,surf }}$ is large is dust then a value for the imaginary refractive index $(k)$ for dust in this region is estimated from Mie theory. Assuming spherical particles with $d_{\mathrm{p}}=3.5 \mu \mathrm{m}$ with density $=2 \mathrm{~g} \mathrm{~cm}^{-3}$ and a real refractive index of either 1.5 or 1.6 , the $k$ is $\sim 0.0035 i$. However, this estimate assumes that all of the $\mathrm{PM}_{\text {super }}$ mass is dust and that no other absorbing species contribute. If some of the $\mathrm{PM}_{\text {super }}$ mass is attributed to non-dust species, then the derived dust-specific MAC and $k$ would be larger. Alternatively, if $\mathrm{BC}$ contributes substantially to the observed supermicron absorption, which seems likely, then the dust-specific MAC and $k$ would be smaller. Most likely, the above values are upper limits. Despite these uncertainties, the observed MAC and $k$ are similar to reported estimates for dust in the Xianghe area in China, where $\mathrm{MAC}_{\text {dust }}=0.048 \mathrm{~m}^{2} \mathrm{~g}^{-1}$ at $520 \mathrm{~nm}$ and where the reported MAC has been adjusted to a density of $2.0 \mathrm{~g} \mathrm{~cm}^{-3}$ (Yang et al., 2009). Overall, although the contribution of supermicron particles to the total absorption is small in this region, it nonetheless must be considered.

\subsubsection{Relationship between scattering and absorption}

There has been increasing interest in the relationship between the absorption Ångström exponent and the scattering Ångström exponent (Yang et al., 2009; Russell et al., 2010; Bahadur et al., 2012; Giles et al., 2012; Cazorla et al., 2013; Costabile et al., 2013). The wide range of SAE values observed here allows for assessment of the AAE vs. SAE relationship in a constrained environment. The observed $\mathrm{AAE}_{532-660}$ vs. $\mathrm{SAE}_{450-550}$ relationships for $\mathrm{PM}_{10}$, submicron and supermicron particles are shown in Fig. 8a-c. The observed AAE values at both sites fall in a fairly narrow range centered around 1.2 for $\mathrm{PM}_{10}$ and submicron particles, with much greater scatter for supermicron particles, consistent with Fig. 5. The submicron SAE values are $>1.8$ and the supermicron SAE values are generally $<0.2$, while the $\mathrm{PM}_{10} \mathrm{SAE}$ values span the range 0.3-2. The wide range of $\mathrm{SAE}$ values for $\mathrm{PM}_{10}$ results from time-varying contributions of supermicron and submicron particles to the total scattering. Very similar results as shown in Fig. 8 are obtained for both $\mathrm{T} 0$ and $\mathrm{T} 1$ when the other wavelength pairs are used (not shown).

Cazorla et al. (2013) proposed a classification scheme based on the position in the $\mathrm{AAE}_{462-648}$ vs. $\mathrm{SAE}_{450-700}$ space (cf. their Fig. 1). They classified particles with $\mathrm{AAE}<1$ and $\mathrm{SAE}>1.5$ as EC-dominated, where EC stands for elemental carbon (which is approximately equivalent to BC; Andreae and Gelencser, 2006; Lack et al., 2014). Here, almost none of the observations fall in this space, despite the submicron absorption being dominated by black carbon. Instead, the submicron measurements fall primarily in the space encompassed by $1<\mathrm{AAE}<1.5$ and $\mathrm{SAE}>2$, which Cazorla et al. (2013) classified as an EC/OC mixture and where an implicit assumption was that the OC (organic carbon) was absorbing in nature (i.e., $\mathrm{BrC}$ ), thus leading to the elevated AAE values compared to the EC-dominated region. These in situ measurements therefore suggest that the EC/OC mixture region should better be classified as EC-dominated (or 

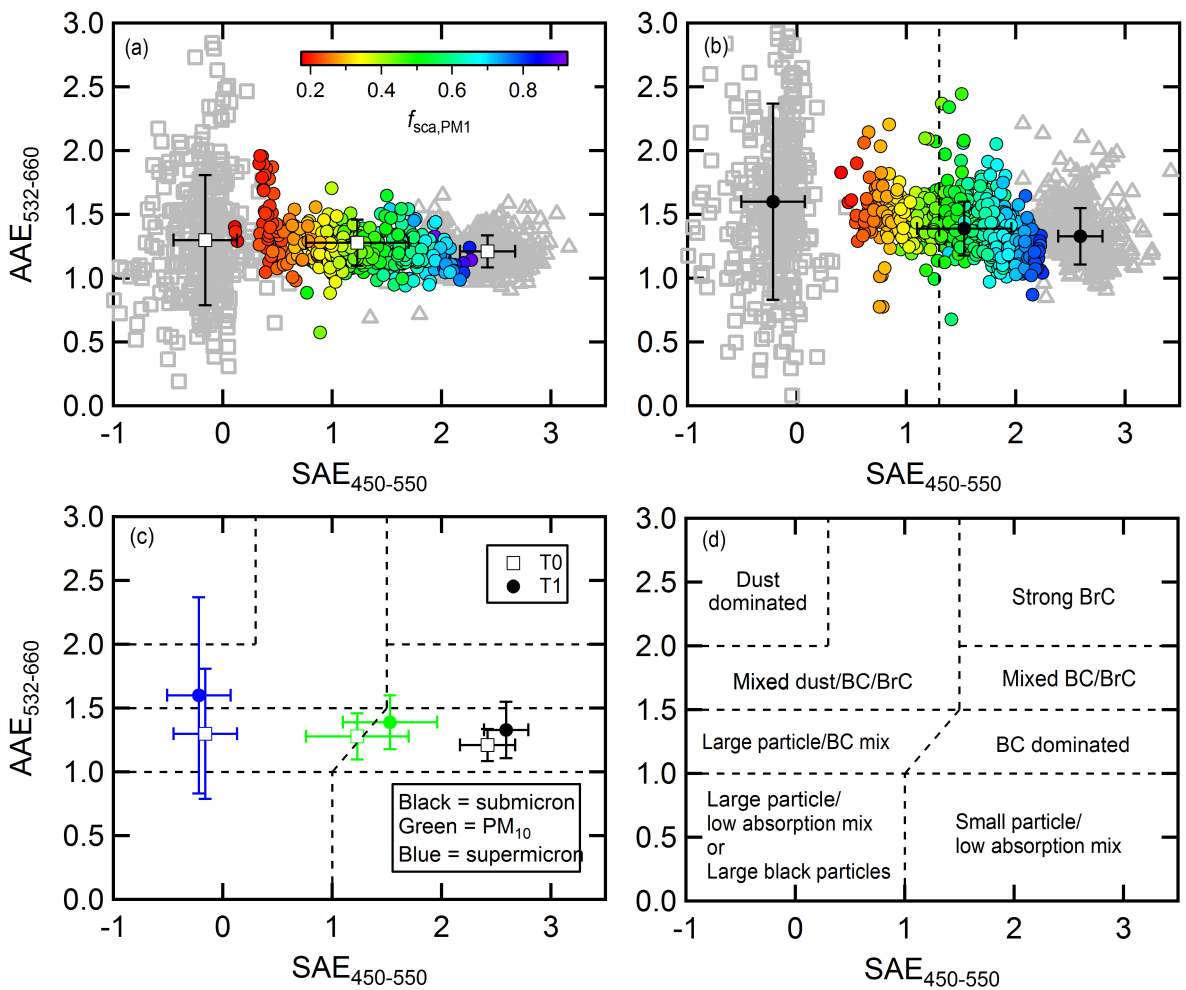

Figure 8. Observed relationship between the AAE (532-600 nm pair) and the SAE (450-550 nm pair) for PM 10 (colored circles), submicron (open gray triangles) and supermicron (open gray squares) particles for the (a) T0 and (b) T1 sites. (c) Comparison between the PM 10 (green), submicron (black) and supermicron (blue) particle averages between the T0 (filled circles) and T1 (open squares) sites. (d) An alternate classification scheme to that suggested by Cazorla et al. (2013).

equivalently BC-dominated). These measurements indicate that $\mathrm{BrC}$ contributions to submicron absorption can only be clearly identified if the AAE is well above 1.5. Given that almost none of the submicron AAE values were $<1$, the suggestion by Bahadur et al. (2012) that a "low-end baseline" AAE value of $0.55( \pm 0.24)$ that is related to "pure EC" seems unlikely to be correct and is more likely a result of a subset of the data points considered in that study having large uncertainties due to low signal levels. (Lower AAE values can be obtained if a wavelength pair is selected in which the wavelengths differ substantially and there is curvature in the $b_{\mathrm{abs}}$ vs. wavelength relationship (Bergstrom et al., 2007).) This conclusion is consistent with that of Russell et al. (2010) and with the in situ observations of Yang et al. (2009) and the remote sensing observations of Giles et al. (2012).

Cazorla et al. (2013) also classified particles having $1<\mathrm{AAE}<1.5$ and $\mathrm{SAE}<1$ as being a "dust/EC mix", and those with $\mathrm{AAE}<1$ and $\mathrm{SAE}<1$ as being "coated large particles". As the supermicron contribution to scattering increases (and the SAE decreases), the observed AAE values, at T1 especially, do not strongly deviate from the 11.5 range. The supermicron particles sampled here were a mixture of sea spray and dust in varying amounts. This therefore suggests that the dust/EC mix regime should be reclas- sified to be more general, as it is not specific to dust, only to large particle/BC mixtures. The measurements suggest that dust contributions can only be clearly elucidated when the $\mathrm{AAE}>1.5$, although even when such large $\mathrm{AAE}$ values are observed, care must be taken if the absolute absorption values are small (as is the case here for supermicron particles), corresponding to individual AAE values with substantial uncertainties. Similar caution is suggested for identification of particles in the coated large particle regime, as classified by Cazorla et al. (2013). The in situ measurements here suggest that observations that fall within this regime are likely the result of measurement uncertainties due to low signal levels, and do not correspond to the presence of coated large particles. Based on the observations here, a new classification scheme using the AAE and SAE relationship is proposed (Fig. 8d).

\subsubsection{Light backscattering}

The extent to which particles scatter light in the backward versus forward direction has an important controlling influence on their climate impacts, namely the amount of incident solar radiation that is reflected back to space and the associated radiative forcing (Haywood and Shine, 1995). Furthermore, the backscatter fraction and asymmetry parame- 

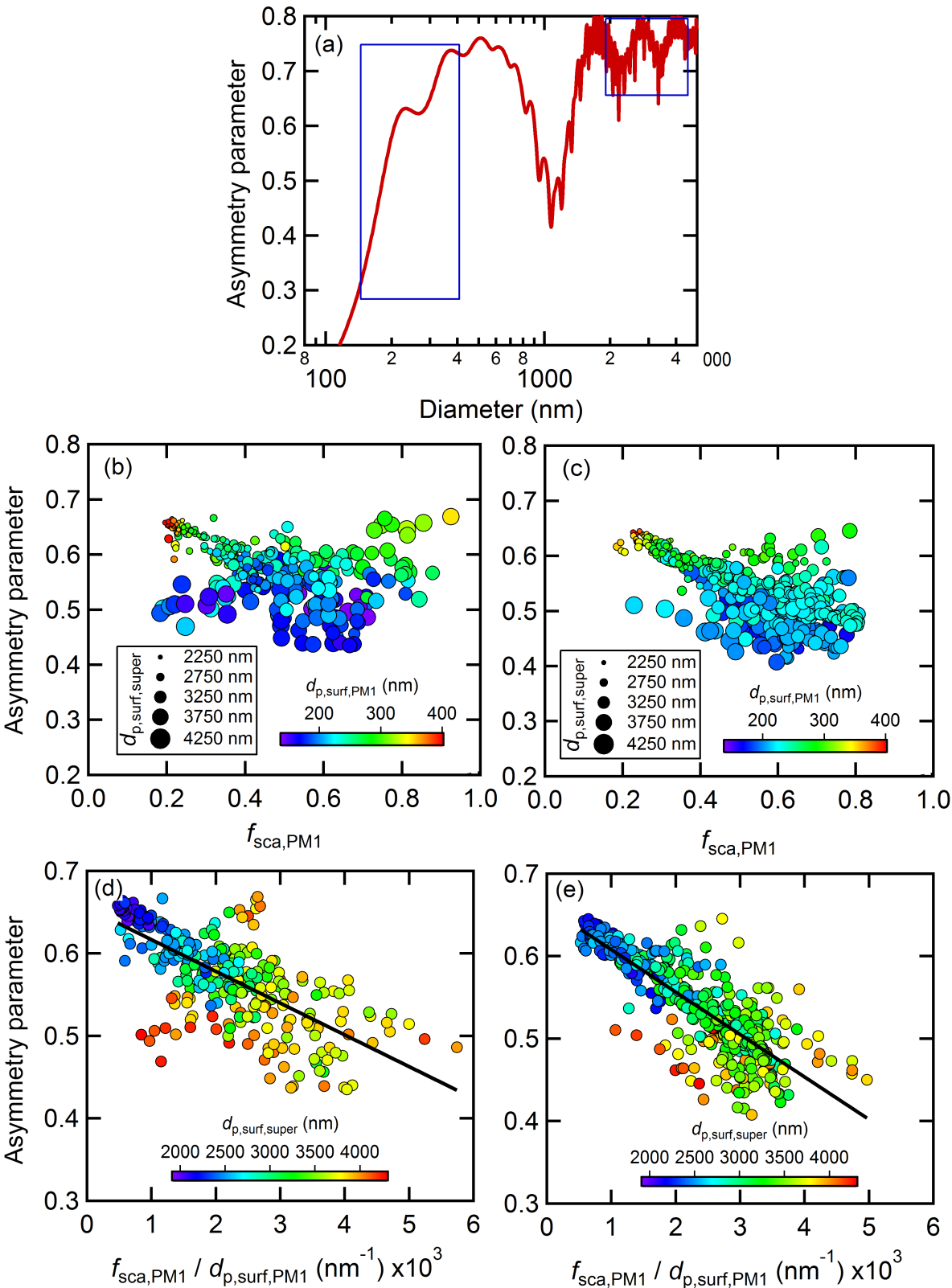

Figure 9. (a) Theoretical variation in the asymmetry parameter, $g_{\text {sca }}$, with particle diameter, assuming spherical particles with

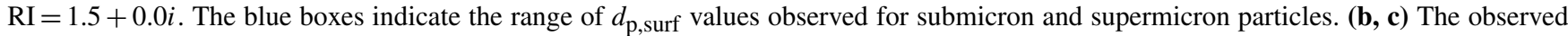
dependence of $g_{\text {sca }}$ on $f_{\text {sca, } \mathrm{PM}_{1}}$ for (b) T0 and (c) T1. The points are colored according to $d_{\mathrm{p}, \text { surf,PM }}$ and the point size corresponds to $d_{\mathrm{p} \text {,surf,super. }}$ (d, e) The relationship between $g_{\mathrm{sca}}$ and $R_{\mathrm{g}}=f_{\mathrm{sca}, \mathrm{PM}_{1}} / d_{\mathrm{p}, \text { surf,PM}}$ for (d) $\mathrm{T} 0$ and (e) T1. The points are colored according to $d_{\mathrm{p}, \text { surf,super. }}$.

ter are important products of remote sensing retrievals. The backscatter fractions at $550 \mathrm{~nm}$ for $\mathrm{PM}_{10}, f_{\text {bsca, } 550, \mathrm{PM}_{10}}$, measured by the nephelometer ranged from 0.1 to 0.23 , with an average value of $0.137 \pm 0.024$ for $\mathrm{T} 0$ and $0.155 \pm 0.054$ for T1. These correspond to a $g_{\text {sca }}$ range for $\mathrm{PM}_{10}$ of 0.40 to 0.67 and mean values of $0.57 \pm 0.056$ for $\mathrm{T} 0$ and $0.53 \pm 0.054$ for $\mathrm{T} 1$. This range of observed values is comparable to measurements made at other locations (Andrews et al., 2006), but the averages are somewhat smaller than $g_{\text {sca }}$ values calculated by Kassianov et al. (2012) at $500 \mathrm{~nm}$ for the T0 and T1 sites (both $g_{\text {sca }, 500}=0.65$ ). The observed $g_{\text {sca }}$ versus $f_{\text {sca, }, \mathrm{PM}_{1}}$ relationship is shown in Fig. 9b and c for T0 and T1. There is a general decrease in $g_{\text {sca }}$ when $f_{\text {sca, } \mathrm{PM}_{1}}$ increases at both sites, more clearly at $\mathrm{T} 1$ than at $\mathrm{T} 0$, but at both sites there is substantial scatter in the data. Some of this scatter appears to be driven by variations in the size of the submicron 
mode, as characterized by $d_{\mathrm{p} \text {,surf,PM}}$. In general, for a given $f_{\text {sca, } \mathrm{PM}_{1}}$ the observed $g_{\text {sca }}$ values are smaller when $d_{\mathrm{p}, \text { surf, } \mathrm{PM}_{1}}$ is smaller.

This observed behavior is generally consistent with theoretical expectations. The theoretical relationship between $g_{\text {sca }}$ and particle size for spherical particles is shown in Fig. 9a. The calculated $g_{\text {sca }}$ increases nearly monotonically for diameters up to about $500 \mathrm{~nm}$, reaching $g_{\text {sca }} \sim 0.75$. In the supermicron range above $1.5 \mu \mathrm{m}$ the $g_{\text {sca }}$ is relatively constant around 0.75 . In between $500 \mathrm{~nm}$ and $1.5 \mu \mathrm{m}$, the $g_{\text {sca }}$ exhibits a more complicated dependence on size. The steepness of the $g_{\text {sca }}$ versus $d_{\mathrm{p}}$ relationship between 100 and $500 \mathrm{~nm}$ means that the observed $g_{\text {sca }}$ for $\mathrm{PM}_{10}$ will be particularly sensitive to variations in the submicron particle size distribution. However, the $g_{\text {sca }}$ will be less sensitive to variations in the supermicron particle size distribution because the $d_{\mathrm{p}}$ versus $g_{\text {sca }}$ relationship is generally flatter. Further, we might expect some relationship between $g_{\text {sca }}$ and the fraction of scattering due to sub- or supermicron particles to the extent that the two size regimes have generally distinct $g_{\text {sca }}$ values. Indeed, such behavior is seen in the observations, in large part because the $d_{\mathrm{p} \text {,surf,PM}}$ values vary within the sensitive range $(100-500 \mathrm{~nm})$.

Therefore, in an effort to account for this apparent codependence of $g_{\text {sca }}$ on $f_{\text {sca, } \mathrm{PM}_{1}}$ and $d_{\mathrm{p}, \text { surf, } \mathrm{PM}_{1}}$, the $f_{\text {sca, } \mathrm{PM}}$ values have been divided by the $d_{\mathrm{p}, \text { surf, } \mathrm{PM}_{1}}$ values, with the ratio indicated as $R_{\mathrm{g}}$. There is, in general, a much stronger relationship between the $g_{\text {sca }}$ values and $R_{\mathrm{g}}$ (Fig. $9 \mathrm{~d}$ and e) than there is with $f_{\mathrm{sca}, \mathrm{PM}_{1}}$ alone, and much of the residual scatter seems to be driven by variations in the supermicron size distribution. Linear fits give $g_{\text {sca }}=-38.5 R_{\mathrm{g}}+0.66$ for T0 $\left(r^{2}=0.51\right)$ and $g_{\text {sca }}=-51.5 R_{\mathrm{g}}+0.66$ for $\mathrm{T} 1\left(r^{2}=0.71\right)$, and where $d_{\mathrm{p}, \text { surf, } \mathrm{PM}_{1}}$ is in nanometers. Overall, the observations here demonstrate that the observable backscatter coefficients depend importantly on the relative contributions of sub- versus supermicron particles to the total scattering, but that the specific relationship between backscatter and the sub- or supermicron scattering fraction is obscured by variations in the size distribution within each size range. However, the greatest sensitivity of $g_{\text {sca }}$ is found for size variations within the submicron size range.

\subsection{Influence of heating on optical properties}

At the T0 site, the UCD CRD and PAS instruments sampled alternately dried, ambient particles $\left(\mathrm{PM}_{2.5}\right)$ or particles that had been passed through a thermodenuder (TD) that was held at $225^{\circ} \mathrm{C}$ during the study. As particles pass through the TD, some materials evaporate, including ammonium nitrate, ammonium sulfate and many organics, while others do not, including black carbon, dust and sea salt. Loss of these materials leads to changes in the optical properties, including the particle optically weighted hygroscopicity. The influence of heating on the optical properties is used here to further probe the particle composition.

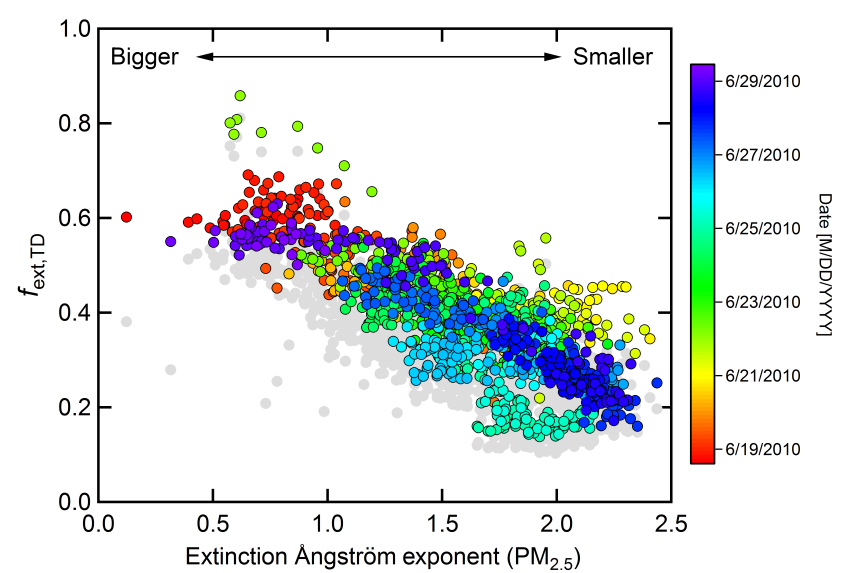

Figure 10. Variation of the extinction fraction remaining at $532 \mathrm{~nm}$ (colored points) and $405 \mathrm{~nm}$ (gray points) as a function of the observed ambient particle extinction Ångström exponent for $\mathrm{PM}_{2.5}$. The points are colored by date.

The observed fraction of extinction remaining after heating, $f_{\text {ext,TD }}$, for $\mathrm{PM}_{2.5}$ varied from $\sim 0.15$ to 0.6 , suggesting a wide range of particle volatility. This variability is strongly linked to the relative contribution of sub- versus supermicron particles to the observed extinction; an approximately linear relationship (with a negative slope) between $f_{\text {ext,TD }}$ and the EAE measured for the ambient particles was observed (Fig. 10). This increase in $f_{\text {ext,TD }}$ with decreasing EAE suggests that the supermicron components are mostly non-volatile, consistent with a likely dust or sea-salt contribution as identified above. Further, this suggests that $f_{\text {ext,TD }}$ can be used as an indicator of coarse-mode fraction in the current study. There is a cluster of points at the highest $f_{\text {ext,TD }}$ (the light green points in Fig. 10) that were observed during a specific overnight period when we suspect that the site was briefly impacted by large particles produced as part of local road resurfacing.

The bulk particle hygroscopicity, characterized by $\gamma_{\mathrm{RH}}$, did not vary monotonically with $f_{\text {ext,TD }}$ (Fig. 11a). This is because the observed hygroscopicity depends on compositional variability within both the sub- and supermicron modes (Atkinson et al., 2015). However, the change in the hygroscopicity upon heating, $\Delta \gamma_{\mathrm{RH}}=\gamma_{\mathrm{RH} \text {,ambient }}-\gamma_{\mathrm{RH}, \mathrm{TD}}$, does exhibit a clear correlation with $f_{\text {ext,TD, with larger }}$ $\Delta \gamma_{\mathrm{RH}}$ corresponding to smaller $f_{\text {ext,TD }}$, i.e., for smaller, typically more volatile particles (Fig. 11b). The observed $\Delta \gamma_{\mathrm{RH}}$ appears to cross over zero around $f_{\mathrm{ext}, \mathrm{TD}}=0.4$. Apparently, for smaller particles that exhibit greater overall mass loss upon heating, the $\gamma_{\mathrm{RH}}$ tends to decrease with heating. This is as might be expected, since one key residual component will be nonhygroscopic $\mathrm{BC}$ when the distribution is dominated by smaller particles. However, when the distribution is dominated by larger particles, evaporation leads to the residual particles appearing, on average, slightly more hygroscopic. This suggests that the supermicron components that are sus- 

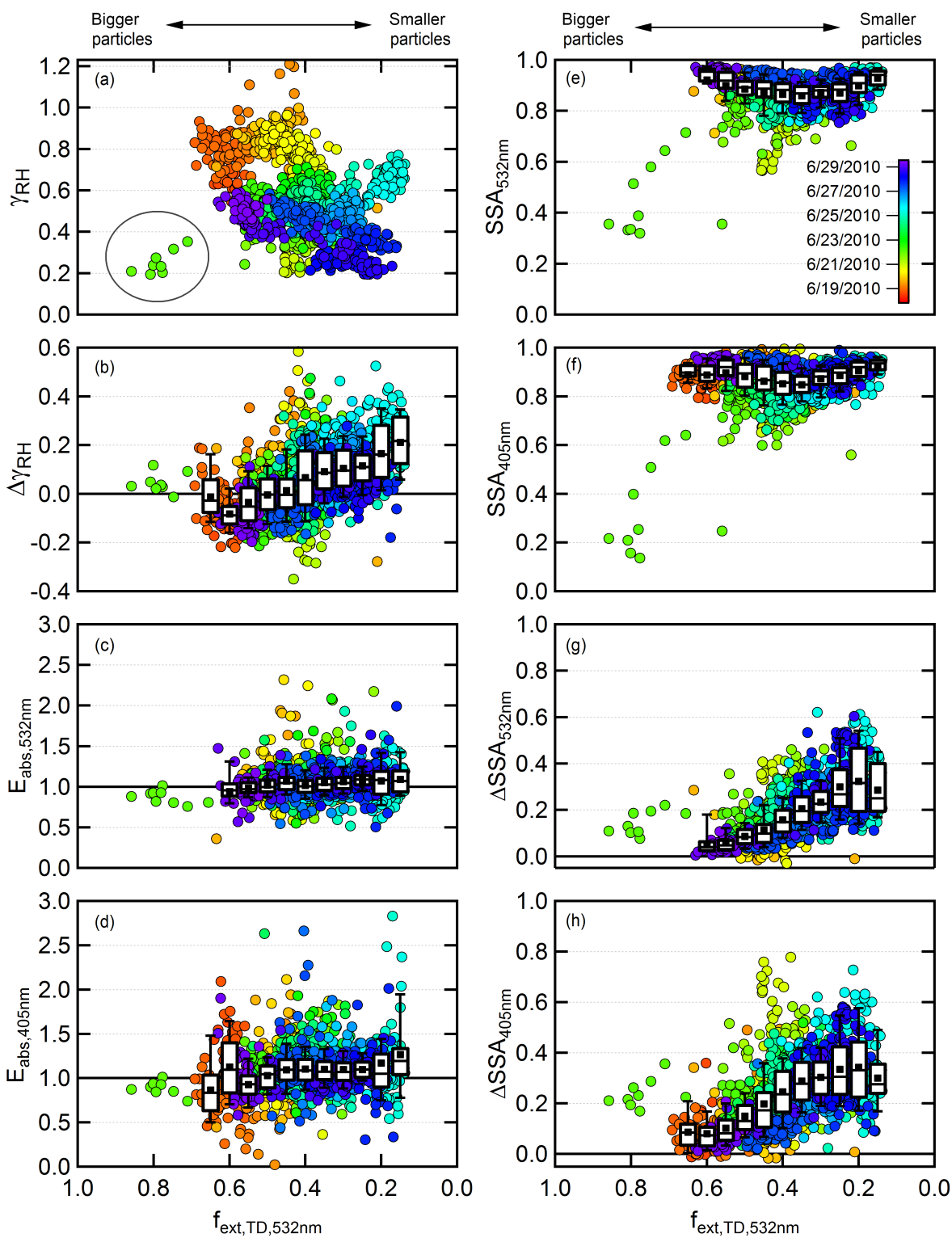

Figure 11. Dependence of various intensive parameters on the fraction of extinction remaining after heating in the thermodenuder. Data are shown for (a) the absolute $\gamma_{\mathrm{RH}}$, (b) the change in $\gamma_{\mathrm{RH}}$, (c) the absorption enhancement at $532 \mathrm{~nm}$, (d) the absorption enhancement at $405 \mathrm{~nm}$, (e) the SSA at $532 \mathrm{~nm}$, (f) the SSA at $405 \mathrm{~nm}$, (g) the change in SSA at $532 \mathrm{~nm}$ and (h) the change in SSA at $405 \mathrm{~nm}$. The points are colored by time. The circled points in (a) show the period that was impacted by local road resurfacing activities.

ceptible to evaporation are lower hygroscopicity material, most likely organics but also, potentially, inorganics such as ammonium sulfate and ammonium nitrate, which have lower hygroscopicity than sodium chloride. Some of the sea-saltcontaining particles observed during CARES were found to be internally mixed with organics (likely organic acids) that displaced chloride (Laskin et al., 2012), and organic salts are generally less hygroscopic than sea salt (Drozd et al., 2014). It is possible that these organics evaporated in the TD, leaving behind more hygroscopic material, although such a hypothesis requires further investigation. It is alternatively pos- sible that the thermodenuding removed residual water that did not fully evaporate in the dryer due to the presence of magnesium sea salts (which do not effloresce until very low $\mathrm{RH}$ ), leading to an apparent increase in the hygroscopicity of the thermodenuded particles. However, the potential impact from this is expected to have been quite limited, given the small amount of residual water retained by magnesium salts at low RH (Gupta et al., 2015).

The contribution to the total light absorption from non-BC materials that evaporate in the TD was characterized by the absorption enhancement, $E_{\text {abs }}$, which is taken here as the ra- 
tio between the ambient and thermodenuded $b_{\text {abs. }}$. We have previously investigated the dependence of $E_{\mathrm{abs}}$ on photochemical age at CARES using the same data set as is being considered here, and separately the dependence on the relative amount of coating (non-BC) material that is internally mixed with BC at the CalNex field study (Cappa et al., 2012). It was found that the $E_{\text {abs }}$ increases by only a small amount as PCA and coating amount increased. Here, we see that $E_{\text {abs }}$ exhibits some slight dependence on $f_{\text {ext,TD }}$, with somewhat larger values observed at smaller $f_{\text {ext,TD }}$ (Fig. 11c and d). It is difficult to establish whether this dependence indicates that larger $E_{\text {abs }}$ would have been observed in Cappa et al. (2012) for the CARES data set had more material evaporated, but given that the $f_{\text {ext,TD }}$ here is determined predominately by changes in the relative contributions from sub- and supermicron particles, this seems unlikely. (The complementary measurements from CalNex were for $\mathrm{PM}_{1}$, not $\mathrm{PM}_{2.5}$ as here, and thus the influence of supermicron particles on the observations was substantially smaller during that study. For reference, the CalNex campaign-average submicron SAE for the $450-550 \mathrm{~nm}$ pair was 2.1. Thus, the conclusions here for the CARES data set are not necessarily applicable to the interpretation of the CalNex data set.) Further, a fit of the mean binned values of $E_{\mathrm{abs}}$ extrapolated to $f_{\mathrm{ext}, \mathrm{TD}}=0$ gives only $E_{\text {abs }}=1.14( \pm 0.02)$ and $1.29( \pm 0.06)$ at 532 and $405 \mathrm{~nm}$, respectively, suggesting that substantially larger values than the observed range would not have been likely had a greater extent of evaporation been observed. The larger extrapolated value at $405 \mathrm{~nm}$ than at $532 \mathrm{~nm}$ is consistent with a small contribution from so-called "brown carbon", which has an absorption spectrum that strongly increases towards shorter wavelengths, to the observed absorption.

The particle single scatter albedo exhibits a nonmonotonic dependence on $f_{\text {ext,TD }}$ at both 532 and $405 \mathrm{~nm}$ (Fig. 11e and f). On average, the ambient SSA values are at a minimum of 0.85 around $f_{\text {ext,TD }}=0.35$. The SSA then increases at either larger or smaller $f_{\text {ext,TD }}$. The increase in

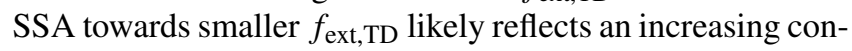
tribution of secondary aerosol species within the submicron mode (e.g., organics, ammonium sulfate, ammonium nitrate) relative to $\mathrm{BC}$, leading the overall particulates to appear both more volatile and leading to more scattering. Indeed, HRAMS measurements indicate that secondary inorganic and organic species are dominant components of the submicron particles in the Sacramento and Sierra Nevada foothill region during CARES (Setyan et al., 2012; Shilling et al., 2013). The increase in SSA towards larger $f_{\text {ext,TD }}$ likely results from the increasing contribution of non-volatile sea salt and dust components within the supermicron mode that are either non-absorbing or very weakly absorbing. Looking at the change in SSA upon heating in the TD, $\triangle$ SSA, there is a clear increase in $\triangle \mathrm{SSA}$ with decreasing $f_{\text {ext,TD }}$ (Fig. $11 \mathrm{~g}$ and $\mathrm{h}$ ). This is as expected because if material does not evaporate then no change in SSA should be observed. The $\Delta \mathrm{SSA}$ linearly extrapolated to $f_{\mathrm{ext}, \mathrm{TD}}=0$ is $0.46( \pm 0.02)$ and $0.50( \pm 0.02)$ at 532 and $405 \mathrm{~nm}$, respectively, corresponding to absolute extrapolated SSA values of $\sim 0.4$ given the observed ambient particle SSA values. (Linear extrapolation to zero is not fully justifiable because the $f_{\text {ext,TD }}$ cannot go to zero if there is some $\mathrm{BC}$ around or if there are other non-volatile materials and because there appears to be some flattening off in the $\Delta$ SSA values at smaller $f_{\text {ext,TD. Nonethe- }}$ less, it can provide an estimate in the limit of small BC contributions.) These extrapolated SSA values are relatively large compared to some laboratory observations for "fresh" BC particles that are produced, for example, from flames (Cross et al., 2010) or gasoline or diesel vehicles (Schnaiter et al., 2005; Forestieri et al., 2013) and that have little intrinsic organic material, but slightly smaller than that reported by one other laboratory study on flame-generated soot (Radney et al., 2014). Primary emitted BC has a fractal-like structure that is thought to collapse over time through atmospheric aging processes. This change in shape due to collapse is thought to lead to an increase in the SSA, separate from any contributions from scattering coating materials (Chakrabarty et al., 2014). The fact that the extrapolated SSA values are larger than many of the laboratory studies on fresh BC suggests that the sampled particles were somewhat collapsed compared to their emitted state. However, if non-absorbing and nonvolatile materials remained (e.g., sea salt), then the extrapolated SSA would not be fully representative of pure BC particles, confounding straightforward interpretation in terms of morphological changes.

For the period where the $\mathrm{T} 0$ site was impacted by particles emitted from local road surfacing activities (e.g., asphalt), the ambient SSA values are small and the $\triangle$ SSA values deviate from the general relationship observed for other periods. In fact, the absolute SSA measured for thermodenuded particles during this particular period are around zero at $405 \mathrm{~nm}$ but $\sim 0.2$ at $532 \mathrm{~nm}$. Such very small SSA values suggest that absorption is dominated by very small particles, or at least particles that are agglomerates of very small spherules; the surface-area-weighted size distribution measured during this period peaked around $300 \mathrm{~nm}$ diameter and the SP2 BC particle size distributions clearly indicate that the overall $\mathrm{BC}$ particle size was larger during the asphalt-impacted period (Fig. S11), suggesting that agglomerates of small spherules are most plausible. We cannot entirely rule out the possibility that the measurements during this period were strongly impacted by some absorbing gas-phase species (e.g., $\mathrm{NO}_{2}$ ), confounding the SSA measurements, although there was no evidence of gas-phase absorption in the background CRD channels during this period, suggesting that this is unlikely.

\section{Conclusions}

Optical property measurements of $\mathrm{PM}_{1}, \mathrm{PM}_{2.5}$ and $\mathrm{PM}_{10}$ made during the CARES 2010 field study have been examined to develop understanding of the relationships between 
various intensive properties and to establish differences in behavior between sub- and supermicron PM. Measurements were made at two sites in the Sacramento region, one urban (T0) and one rural (T1), but were impacted by the urban outflow on most days under southwesterly flow conditions (Fast et al., 2012). At both sites, there is a strong contribution of supermicron particles to the total scattering, averaging around $50 \%$ at both sites. The source of these supermicron particles appears to be a combination of local dust and sea spray, along with some contributions from penetration of traditionally submicron particles into the supermicron mode. The specific contributions of any of these supermicron particle sources varies with time and depends on the prevailing transport patterns with, perhaps not surprisingly, generally larger sea spray contributions when air masses have been transported from the San Francisco Bay Area. The measured scattering Ångström exponents (SAEs) for $\mathrm{PM}_{10}$ are strongly correlated with the submicron versus supermicron fraction of the total scattering, with similar linear relationships observed at both sites. This relationship held despite there being variations in the size distributions within a given mode, which can theoretically alter the SAE. This suggests that the relationships determined here are quite general, and that the SAE can be used to quantitatively attribute scattering to sub- and supermicron particles. There was no notable dependence of the absorption Ångström exponent (AAE) on SAE for $\mathrm{PM}_{10}$, and these observations were used to propose an updated particle classification scheme based on the relationship between these two parameters.

The influence of photochemical processing on the subversus supermicron contribution to scattering differed between the two sites, with photochemical processing leading to an increase in the submicron fraction of scattering for the T0 (urban) site but a minimal change, or even a slight decrease, at the $\mathrm{T} 1$ (downwind) site. This reflects in part the strong daytime peak in photochemical age at the T0 site in contrast to the more gradual increase at the $\mathrm{T} 1$ site, coupled with the much stronger diurnal profile in the wind speed, with a daytime peak, at the T1 site. Consequently, at the T1 site, photochemical production of secondary PM was spread over a wider range of times due to transport and was countered through local, temporally similar increases in dust production due to the higher daytime winds. At the T0 site, the strong photochemical production of secondary PM led to a clear increase in the submicron fraction of scattering with photochemical aging.

The mass scattering coefficient for the supermicron particles varied inversely with the median surface-weighted particle diameter $\left(d_{\mathrm{p}, \text { surf }}\right)$ of the supermicron mode, in general accordance with theoretical expectations. This indicates clear temporal variability in the nature of the supermicron particle sources, which seem to be coupled to the prevailing wind direction or air mass history, as established through consideration of back trajectories. Light absorption was dominated by submicron particles, although there was some contribution from the supermicron particles. The mass absorption coefficient for supermicron particles exhibited a clear dependence on the supermicron $d_{\mathrm{p}, \text { surf }}$, most likely due to variations in the relative contributions of non-absorbing sea spray particles, penetration of $\mathrm{BC}$ from the submicron mode and very weak absorption by supermicron dust particles. Particle backscatter was found to be related to the relative fractions of subversus supermicron scattering, but with an additional sensitivity to variations in the size distribution within the submicron size range. The susceptibility of the particles to heating in a thermodenuder depended explicitly on the contribution of supermicron particles to the $\mathrm{PM}_{2.5}$ extinction, most likely because a large fraction of the supermicron particles were either essentially non-volatile sea spray or dust particles. Heating in general led to an increase in the average particle hygroscopicity and a decrease in the single scatter albedo. These together indicate that the residual particles are likely a combination of absorbing submicron $\mathrm{BC}$ and somewhat hygroscopic supermicron sea spray and less hygroscopic dust. The results presented here demonstrate that optical property measurements can be used to assess likely chemical differences in the contributing particle types, and thus to identify key PM sources.

\section{The Supplement related to this article is available online at doi:10.5194/acp-16-6511-2016-supplement.}

Acknowledgements. This work was supported by the Atmospheric System Research (ASR) program sponsored by the US Department of Energy (DOE), Office of Biological and Environmental Research (OBER), including grant no. DE-SC0008937. The authors acknowledge W. Berk Knighton for the PTR-MS data at the T1 site, R. Subramanian for the SP2 data, Ari Setyan for collection of the SMPS data at the T1 site and B. Tom Jobson for the $\mathrm{NO}_{x}, \mathrm{NO}_{y}, \mathrm{PTR}-\mathrm{MS}$ and meteorological data at the T0 site. The authors acknowledge the NOAA Air Resources Laboratory (ARL) for the provision of the HYSPLIT transport and dispersion model (http://www.ready.noaa.gov) used in this publication. The backscattering Mie calculations were performed using MiePlot from Philip Laven (http://www.philiplaven.com/mieplot.htm). Funding for data collection was provided by the US DOE's Atmospheric Radiation Measurement (ARM) Program. All data used in this study are available from the ARM data archive at http://www.arm.gov/campaigns/aaf2009carbonaerosol. Pacific Northwest National Laboratory is operated for the U.S. Department of Energy by Battelle Memorial Institute under contract DE-AC0676RLO 1830. The views expressed in this document are solely those of the authors and the funding agencies do not endorse any products or commercial services mentioned in this publication.

Edited by: D. J. Cziczo 


\section{References}

Anderson, T. L. and Ogren, J. A.: Determining Aerosol Radiative Properties Using the TSI 3563 Integrating Nephelometer, Aerosol Sci. Tech., 29, 57-69, doi:10.1080/02786829808965551, 1998.

Anderson, T. L., Masonis, S. J., Covert, D. S., Ahlquist, N. C., Howell, S. G., Clarke, A. D., and McNaughton, C. S.: Variability of aerosol optical properties derived from in situ aircraft measurements during ACE-Asia, J. Geophys. Res., 108, 8647, doi:10.1029/2002JD003247, 2003.

Andreae, M. O. and Gelencser, A.: Black carbon or brown carbon? The nature of light-absorbing carbonaceous aerosols, Atmos. Chem. Phys., 6, 3131-3148, doi:10.5194/acp-6-3131-2006, 2006.

Andrews, E., Sheridan, P. J., Fiebig, M., McComiskey, A., Ogren, J. A., Arnott, P., Covert, D., Elleman, R., Gasparini, R., Collins, D., Jonsson, H., Schmid, B., and Wang, J.: Comparison of methods for deriving aerosol asymmetry parameter, J. Geophys. Res.Atmos., 111, D05S04, doi:10.1029/2004JD005734, 2006.

Atkinson, D. B., Radney, J. G., Lum, J., Kolesar, K. R., Cziczo, D. J., Pekour, M. S., Zhang, Q., Setyan, A., Zelenyuk, A., and Cappa, C. D.: Aerosol optical hygroscopicity measurements during the 2010 CARES campaign, Atmos. Chem. Phys., 15, 40454061, doi:10.5194/acp-15-4045-2015, 2015.

Atkinson, R., Baulch, D. L., Cox, R. A., Crowley, J. N., Hampson, R. F., Hynes, R. G., Jenkin, M. E., Rossi, M. J., Troe, J., and Subcommittee, I.: Evaluated kinetic and photochemical data for atmospheric chemistry: Volume II - gas phase reactions of organic species, Atmos. Chem. Phys., 6, 3625-4055, doi:10.5194/acp-63625-2006, 2006.

Bahadur, R., Praveen, P. S., Xu, Y., and Ramanathan, V.: Solar absorption by elemental and brown carbon determined from spectral observations, P. Natl. Acad. Sci. USA, 109, 17366-17371, doi:10.1073/pnas.1205910109, 2012.

Bates, T. S., Anderson, T. L., Baynard, T., Bond, T., Boucher, O., Carmichael, G., Clarke, A., Erlick, C., Guo, H., Horowitz, L., Howell, S., Kulkarni, S., Maring, H., McComiskey, A., Middlebrook, A., Noone, K., O’Dowd, C. D., Ogren, J., Penner, J., Quinn, P. K., Ravishankara, A. R., Savoie, D. L., Schwartz, S. E., Shinozuka, Y., Tang, Y., Weber, R. J., and Wu, Y.: Aerosol direct radiative effects over the northwest Atlantic, northwest Pacific, and North Indian Oceans: estimates based on in-situ chemical and optical measurements and chemical transport modeling, Atmos. Chem. Phys., 6, 1657-1732, doi:10.5194/acp-6-1657-2006, 2006.

Bergstrom, R. W., Pilewskie, P., Russell, P. B., Redemann, J., Bond, T. C., Quinn, P. K., and Sierau, B.: Spectral absorption properties of atmospheric aerosols, Atmos. Chem. Phys., 7, 5937-5943, doi:10.5194/acp-7-5937-2007, 2007.

Bohren, C. F. and Huffman, D. R.: Absorption and scattering of light by small particles, Wiley-VCH Verlag $\mathrm{GmbH}$, Weinheim, Germany, 57-81, 1998.

Bond, T. C., Anderson, T. L., and Campbell, D.: Calibration and intercomparison of filter-based measurements of visible light absorption by aerosols, Aerosol Sci. Tech., 30, 582-600, doi:10.1080/027868299304435, 1999.

Brown, S. S., Talukdar, R. K., and Ravishankara, A. R.: Rate constants for the reaction $\mathrm{OH}+\mathrm{NO}_{2}+\mathrm{M}+\mathrm{HNO}_{3}+\mathrm{M}$ un- der atmospheric conditions, Chem. Phys. Lett., 299, 277-284, doi:10.1016/S0009-2614(98)01283-4, 1999.

California Air Resources Board: Characterization of ambient $\mathrm{PM}_{10}$ and $\mathrm{PM}_{2.5}$ in California, Sacramento, CA, http://www. arb.ca.gov/pm/pmmeasures/pmch05/pmch05.htm (last access: 20 May 2016), 2005.

Canagaratna, M. R., Jayne, J. T., Jimenez, J. L., Allan, J. D., Alfarra, M. R., Zhang, Q., Onasch, T. B., Drewnick, F., Coe, H., Middlebrook, A., Delia, A., Williams, L. R., Trimborn, A. M., Northway, M. J., DeCarlo, P. F., Kolb, C. E., Davidovits, P., and Worsnop, D. R.: Chemical and microphysical characterization of ambient aerosols with the Aerodyne aerosol mass spectrometer, Mass Spectrom. Rev., 26, 185-222, doi:10.1002/mas.20115, 2007.

Cappa, C. D., Onasch, T. B., Massoli, P., Worsnop, D., Bates, T. S., Cross, E., Davidovits, P., Hakala, J., Hayden, K., Jobson, B. T., Kolesar, K. R., Lack, D. A., Lerner, B., Li, S. M., Mellon, D., Nuaanman, I., Olfert, J., Petaja, T., Quinn, P. K., Song, C., Subramanian, R., Williams, E. J., and Zaveri, R. A.: Radiative absorption enhancements due to the mixing state of atmospheric black carbon, Science, 337, 1078-1081, doi:10.1126/science.1223447, 2012.

Cappa, C. D., Williams, E. J., Lack, D. A., Buffaloe, G. M., Coffman, D., Hayden, K. L., Herndon, S. C., Lerner, B. M., Li, S. M., Massoli, P., McLaren, R., Nuaaman, I., Onasch, T. B., and Quinn, P. K.: A case study into the measurement of ship emissions from plume intercepts of the NOAA Ship Miller Freeman, Atmos. Chem. Phys., 14, 1337-1352, doi:10.5194/acp-14-13372014, 2014.

Cazorla, A., Bahadur, R., Suski, K. J., Cahill, J. F., Chand, D., Schmid, B., Ramanathan, V., and Prather, K. A.: Relating aerosol absorption due to soot, organic carbon, and dust to emission sources determined from in-situ chemical measurements, Atmos. Chem. Phys., 13, 9337-9350, doi:10.5194/acp-13-9337-2013, 2013.

Chakrabarty, R. K., Beres, N. D., Moosmuller, H., China, S., Mazzoleni, C., Dubey, M. K., Liu, L., and Mishchenko, M. I.: Soot superaggregates from flaming wildfires and their direct radiative forcing, Scient. Rep., 4, 5508, doi:10.1038/srep05508, 2014.

Chung, C. E., Ramanathan, V., and Decremer, D.: Observationally constrained estimates of carbonaceous aerosol radiative forcing, P. Natl. Acad. Sci. USA, 109, 11624-11629, doi:10.1073/pnas.1203707109, 2012.

Clarke, A. and Kapustin, V.: Hemispheric Aerosol Vertical Profiles: Anthropogenic Impacts on Optical Depth and Cloud Nuclei, Science, 329, 1488-1492, doi:10.1126/science.1188838, 2010.

Clarke, A., Shinozuka, Y., Kapustin, V. N., Howell, S., Huebert, B. J., Doherty, S. J., Anderson, T. L., Covert, D., Anderson, J., Hua, X., Moore II, K. G., McNaughton, C., Carmichael, G., and Weber, R.: Size distributions and mixtures of dust and black carbon aerosol in Asian outflow: Physiochemistry and optical properties, J. Geophys. Res., 109, D15S09, doi:10.1029/2003JD004378, 2004.

Costabile, F., Barnaba, F., Angelini, F., and Gobbi, G. P.: Identification of key aerosol populations through their size and composition resolved spectral scattering and absorption, Atmos. Chem. Phys., 13, 2455-2470, doi:10.5194/acp-13-2455-2013, 2013.

Cross, E. S., Onasch, T. B., Ahern, A., Wrobel, W., Slowik, J. G., Olfert, J., Lack, D. A., Massoli, P., Cappa, C. D., Schwarz, J. 
P., Spackman, J. R., Fahey, D. W., Sedlacek, A., Trimborn, A., Jayne, J. T., Freedman, A., Williams, L. R., Ng, N. L., Mazzoleni, C., Dubey, M., Brem, B., Kok, G., Subramanian, R., Freitag, S., Clarke, A., Thornhill, D., Marr, L. C., Kolb, C. E., Worsnop, D. R., and Davidovits, P.: Soot Particle Studies - Instrument InterComparison - Project Overview, Aerosol Sci. Tech., 44, 592611, doi:10.1080/02786826.2010.482113, 2010.

Cziczo, D. J., Thomson, D. S., Thompson, T. L., DeMott, P. J., and Murphy, D. M.: Particle analysis by laser mass spectrometry (PALMS) studies of ice nuclei and other low number density particles, Int. J. Mass Spectrom., 258, 21-29, doi:10.1016/j.ijms.2006.05.013, 2006.

DeCarlo, P. F., Slowik, J. G., Worsnop, D., Davidovits, P., and Jimenez, J. L.: Particle morphology and density characterization by combined mobility and aerodynamic diameter measurements. Part 1: Theory, Aerosol Sci. Tech., 38, 1185-1205, doi:10.1080/027868290903907, 2004.

Draxler, R. R. and Rolph, G. D.: HYSPLIT (HYbrid Single-Particle Lagrangian Integrated Trajectory) Model access via NOAA ARL READY Website, NOAA Air Resources Laboratory, College Park, MD, USA, http://www.arl.noaa.gov/HYSPLIT.php, last access: 29 August 2015.

Drozd, G., Woo, J., Hakkinen, S. A. K., Nenes, A., and McNeill, V. F.: Inorganic salts interact with oxalic acid in submicron particles to form material with low hygroscopicity and volatility, Atmos. Chem. Phys., 14, 5205-5215, doi:10.5194/acp-14-52052014, 2014.

Dubovik, O., Holben, B., Eck, T. F., Smirnov, A., Kaufman, Y. J., King, M. D., Tanre, D., and Slutsker, I.: Variability of absorption and optical properties of key aerosol types observed in worldwide locations, J. Atmos. Sci., 59, 590-608, 2002.

Dubovik, O. and King, M. D.: A flexible inversion algorithm for retrieval of aerosol optical properties from Sun and sky radiance measurements, J. Geophys. Res.-Atmos., 105, 20673-20696, doi:10.1029/2000JD900282, 2000.

Eck, T. F., Holben, B. N., Sinyuk, A., Pinker, R. T., Goloub, P., Chen, H., Chatenet, B., Li, Z., Singh, R. P., Tripathi, S. N., Reid, J. S., Giles, D. M., Dubovik, O., O’Neill, N. T., Smirnov, A., Wang, P., and Xia, X.: Climatological aspects of the optical properties of fine/coarse mode aerosol mixtures, J. Geophys. Res.Atmos., 115, D19205, doi:10.1029/2010JD014002, 2010.

Ewing, S. A., Christensen, J. N., Brown, S. T., Vancuren, R. A., Cliff, S. S., and Depaolo, D. J.: Pb Isotopes as an Indicator of the Asian Contribution to Particulate Air Pollution in Urban California, Environ. Sci. Technol., 44, 8911-8916, doi:10.1021/es101450t, 2010.

Fast, J. D., Gustafson Jr., W. I., Berg, L. K., Shaw, W. J., Pekour, M., Shrivastava, M., Barnard, J. C., Ferrare, R. A., Hostetler, C. A., Hair, J. A., Erickson, M., Jobson, B. T., Flowers, B., Dubey, M. K., Springston, S., Pierce, R. B., Dolislager, L., Pederson, J., and Zaveri, R. A.: Transport and mixing patterns over Central California during the carbonaceous aerosol and radiative effects study (CARES), Atmos. Chem. Phys., 12, 1759-1783, doi:10.5194/acp-12-1759-2012, 2012.

Forestieri, S. D., Collier, S., Kuwayama, T., Zhang, Q., Kleeman, M. J., and Cappa, C. D.: Real-Time Black Carbon Emission Factor Measurements from Light Duty Vehicles, Environ. Sci. Technol., 47, 13104-13112, doi:10.1021/es401415a, 2013.
Garland, R. M., Yang, H., Schmid, O., Rose, D., Nowak, A., Achtert, P., Wiedensohler, A., Takegawa, N., Kita, K., Miyazaki, Y., Kondo, Y., Hu, M., Shao, M., Zeng, L. M., Zhang, Y. H., Andreae, M. O., and Pöschl, U.: Aerosol optical properties in a rural environment near the mega-city Guangzhou, China: implications for regional air pollution, radiative forcing and remote sensing, Atmos. Chem. Phys., 8, 5161-5186, doi:10.5194/acp-85161-2008, 2008.

Giles, D. M., Holben, B. N., Eck, T. F., Sinyuk, A., Smirnov, A., Slutsker, I., Dickerson, R. R., Thompson, A. M., and Schafer, J. S.: An analysis of AERONET aerosol absorption properties and classifications representative of aerosol source regions, J. Geophys. Res.-Atmos., 117, D17203, doi:10.1029/2012JD018127, 2012.

Ginoux, P., Prospero, J. M., Gill, T. E., Hsu, N. C., and Zhao, M.: Global-scale attribution of anthropogenic and natural dust sources and their emission rates based on MODIS Deep Blue aerosol products, Rev. Geophys., 50, RG3005, doi:10.1029/2012RG000388, 2012.

Gupta, D., Eom, H. J., Cho, H. R., and Ro, C. U.: Hygroscopic behavior of $\mathrm{NaCl}-\mathrm{MgCl}_{2}$ mixture particles as nascent sea-spray aerosol surrogates and observation of efflorescence during humidification, Atmos. Chem. Phys., 15, 11273-11290, doi:10.5194/acp-15-11273-2015, 2015.

Gyawali, M., Arnott, W. P., Lewis, K., and Moosmüller, H.: In situ aerosol optics in Reno, NV, USA during and after the summer 2008 California wildfires and the influence of absorbing and non-absorbing organic coatings on spectral light absorption, Atmos. Chem. Phys., 9, 8007-8015, doi:10.5194/acp-9-8007-2009, 2009.

Gysel, M., Laborde, M., Olfert, J. S., Subramanian, R., and Gröhn, A. J.: Effective density of Aquadag and fullerene soot black carbon reference materials used for SP2 calibration, Atmos. Meas. Tech., 4, 2851-2858, doi:10.5194/amt-4-2851-2011, 2011.

Haywood, J. M. and Shine, K. P.: The Effect of Anthropogenic Sulfate and Soot Aerosol on the Clear-Sky Planetary Radiation Budget, Geophys. Res. Lett., 22, 603-606, doi:10.1029/95GL00075, 1995.

Huffman, J. A., Ziemann, P. J., Jayne, J. T., Worsnop, D. R., and Jimenez, J. L.: Development and characterization of a fast-stepping/scanning thermodenuder for chemically-resolved aerosol volatility measurements, Aerosol Sci. Tech., 42, 395407, doi:10.1080/02786820802104981, 2008.

IPCC: Climate Change 2013: The Physical Science Basis, in: Contribution of Working Group I to the Fifth Assessment Report of the Intergovernmental Panel on Climate Change, Cambridge University Press, Cambridge, UK and New York, NY, USA, Chapter 7, 571-658, 2013.

Jung, J., Lee, H., Kim, Y. J., Liu, X., Zhang, Y., Hu, M., and Sugimoto, N.: Optical properties of atmospheric aerosols obtained by in situ and remote measurements during 2006 Campaign of Air Quality Research in Beijing (CAREBeijing-2006), J. Geophys. Res., 114, D00G02, doi:10.1029/2008JD010337, 2009.

Kassianov, E., Pekour, M., and Barnard, J.: Aerosols in central California: Unexpectedly large contribution of coarse mode to aerosol radiative forcing, Geophys. Res. Lett., 39, L20806, doi:10.1029/2012GL053469, 2012. 
Kaufman, Y. J., Tanre, D., and Boucher, O.: A satellite view of aerosols in the climate system, Nature, 419, 215-223, doi:10.1038/nature01091, 2002.

Laborde, M., Mertes, P., Zieger, P., Dommen, J., Baltensperger, U., and Gysel, M.: Sensitivity of the Single Particle Soot Photometer to different black carbon types, Atmos. Meas. Tech., 5, 10311043, doi:10.5194/amt-5-1031-2012, 2012a.

Laborde, M., Schnaiter, M., Linke, C., Saathoff, H., Naumann, K. H., Möhler, O., Berlenz, S., Wagner, U., Taylor, J. W., Liu, D., Flynn, M., Allan, J. D., Coe, H., Heimerl, K., Dahlkötter, F., Weinzierl, B., Wollny, A. G., Zanatta, M., Cozic, J., Laj, P., Hitzenberger, R., Schwarz, J. P., and Gysel, M.: Single Particle Soot Photometer intercomparison at the AIDA chamber, Atmos. Meas. Tech., 5, 3077-3097, doi:10.5194/amt-5-3077-2012, $2012 b$

Lack, D. A., Moosmüller, H., McMeeking, G. R., Chakrabarty, R. K., and Baumgardner, D. : Characterizing elemental, equivalent black, and refractory black carbon aerosol particles: a review of techniques, their limitations and uncertainties, Anal. Bioanal. Chem., 406, 99-122, doi:10.1007/s00216-013-7402-3, 2014.

Lack, D. A. and Cappa, C. D.: Impact of brown and clear carbon on light absorption enhancement, single scatter albedo and absorption wavelength dependence of black carbon, Atmos. Chem. Phys., 10, 4207-4220, doi:10.5194/acp-10-4207-2010, 2010.

Lack, D. A. and Langridge, J. M.: On the attribution of black and brown carbon light absorption using the Angstrom exponent, Atmos. Chem. Phys., 13, 10535-10543, doi:10.5194/acp13-10535-2013, 2013.

Lack, D. A., Richardson, M. S., Law, D., Langridge, J. M., Cappa, C. D., McLaughlin, R. J., and Murphy, D. M.: Aircraft Instrument for Comprehensive Characterization of Aerosol Optical Properties, Part 2: Black and Brown Carbon Absorption and Absorption Enhancement Measured with Photo Acoustic Spectroscopy, Aerosol Sci. Tech., 46, 555-568, doi:10.1080/02786826.2011.645955, 2012.

Langridge, J. M., Richardson, M. S., Lack, D., Law, D., and Murphy, D. M.: Aircraft Instrument for Comprehensive Characterization of Aerosol Optical Properties, Part I: Wavelength-Dependent Optical Extinction and Its Relative Humidity Dependence Measured Using Cavity Ringdown Spectroscopy, Aerosol Sci. Tech., 45, 1305-1318, doi:10.1080/02786826.2011.592745, 2011.

Laskin, A., Moffet, R. C., Gilles, M. K., Fast, J. D., Zaveri, R. A., Wang, B. B., Nigge, P., and Shutthanandan, J.: Tropospheric chemistry of internally mixed sea salt and organic particles: Surprising reactivity of $\mathrm{NaCl}$ with weak organic acids, J. Geophys. Res.-Atmos., 117, D15302, doi:10.1029/2012jd017743, 2012.

Malm, W. C. and Hand, J. L.: An examination of the physical and optical properties of aerosols collected in the IMPROVE program, Atmos. Environ., 41, 3407-3427, doi:10.1016/j.atmosenv.2006.12.012, 2007.

Malm, W. C., Pitchford, M. L., McDade, C., and Ashbaugh, L. L.: Coarse particle speciation at selected locations in the rural continental United States, Atmos. Environ., 41, 2225-2239, doi:10.1016/j.atmosenv.2006.10.077, 2007.

Myhre, G., Samset, B. H., Schulz, M., Balkanski, Y., Bauer, S., Berntsen, T. K., Bian, H., Bellouin, N., Chin, M., Diehl, T., Easter, R. C., Feichter, J., Ghan, S. J., Hauglustaine, D., Iversen, T., Kinne, S., Kirkevåg, A., Lamarque, J. F., Lin, G., Liu, X., Luo, G., Ma, X., Penner, J. E., Rasch, P. J., Seland, Ø., Skeie, R. B.,
Stier, P., Takemura, T., Tsigaridis, K., Wang, Z., Xu, L., Yu, H., Yu, F., Yoon, J. H., Zhang, K., Zhang, H., and Zhou, C.: Radiative forcing of the direct aerosol effect from AeroCom Phase II simulations, Atmos. Chem. Phys., 13, 1853-1877, doi:10.5194/acp13-1853-2013, 2012.

Nakayama, T., Kondo, Y., Moteki, N., Sahu, L. K., Kinase, T., Kita, K., and Matsumi, Y.: Size-dependent correction factors for absorption measurements using filter-based photometers: PSAP and COSMOS, J. Aerosol Sci., 41, 333-343, doi:10.1016/j.jaerosci.2010.01.004, 2010.

Ogren, J. A.: Comment on "Calibration and Intercomparison of Filter-Based Measurements of Visible Light Absorption by Aerosols", Aerosol Sci. Tech., 44, 589-591, doi:10.1080/02786826.2010.482111, 2010.

Parrish, D. D., Stohl, A., Forster, C., Atlas, E. L., Blake, D. R., Goldan, P. D., Kuster, W. C., and de Gouw, J. A.: Effects of mixing on evolution of hydrocarbon ratios in the troposphere, J. Geophys. Res.-Atmos., 112, D10S34, doi:10.1029/2006JD007583, 2007.

Quinn, P. K., Coffman, D. J., Bates, T. S., Welton, E. J., Covert, D. S., Miller, T. L., Johnson, J. E., Maria, S., Russell, L., Arimoto, R., Carrico, C. M., Rood, M. J., and Anderson, J.: Aerosol optical properties measured on board the Ronald H. Brown during ACE-Asia as a function of aerosol chemical composition and source region, J. Geophys. Res.-Atmos., 109, D19S01, doi:10.1029/2003JD004010, 2004.

Radney, J. G., You, R., Ma, X., Conny, J. M., Zachariah, M. R., Hodges, J. T., and Zangmeister, C. D.: Dependence of Soot Optical Properties on Particle Morphology: Measurements and Model Comparisons, Environ. Sci. Technol., 48, 3169-3176, doi:10.1021/es4041804, 2014.

Roberts, J. M., Fehsenfeld, F. C., Liu, S. C., Bollinger, M. J., Hahn, C., Albritton, D. L., and Sievers, R. E.: Measurements of aromatic hydrocarbon ratios and $\mathrm{NO}_{x}$ concentrations in the rural troposphere - observation of air-mass photochemical aging and $\mathrm{NO}_{x}$ removal, Atmos. Environ., 18, 2421-2432, doi:10.1016/0004-6981(84)90012-x, 1984.

Russell, P. B., Bergstrom, R. W., Shinozuka, Y., Clarke, A. D., DeCarlo, P. F., Jimenez, J. L., Livingston, J. M., Redemann, J., Dubovik, O., and Strawa, A.: Absorption Angstrom Exponent in AERONET and related data as an indicator of aerosol composition, Atmos. Chem. Phys., 10, 1155-1169, doi:10.5194/acp-101155-2010, 2010.

Schnaiter, M., Linke, C., Mohler, O., Naumann, K. H., Saathoff, H., Wagner, R., Schurath, U., and Wehner, B.: Absorption amplification of black carbon internally mixed with secondary organic aerosol, J. Geophys. Res.-Atmos., 110, D019204, doi:10.1029/2005JD006046, 2005.

Schuster, G. L., Dubovik, O., and Holben, B. N.: Angstrom exponent and bimodal aerosol size distributions, J. Geophys. Res.Atmos., 111, D07207, doi:10.1029/2005JD006328, 2006.

Schwarz, J. P., Gao, R. S., Fahey, D. W., Thomson, D. S., Watts, L. A., Wilson, J. C., Reeves, J. M., Darbeheshti, M., Baumgardner, D. G., Kok, G. L., Chung, S. H., Schulz, M., Hendricks, J., Lauer, A., Karcher, B., Slowik, J. G., Rosenlof, K. H., Thompson, T. L., Langford, A. O., Loewenstein, M., and Aikin, K. C.: Single-particle measurements of midlatitude black carbon and light-scattering aerosols from the boundary layer to 
the lower stratosphere, J. Geophys. Res.-Atmos., 111, D16207, doi:10.1029/2006jd007076, 2006.

Schwartz, S. E.: The whitehouse effect-Shortwave radiative forcing of climate by anthropogenic aerosols: an overview, J. Aerosol Sci., 27, 359-382, doi:10.1016/0021-8502(95)00533-1, 1996.

Seinfeld, J. H. and Pandis, S. N.: Atmospheric chemistry and physics: from air pollution to climate change, Wiley, New York, 100-103, 1998.

Setyan, A., Zhang, Q., Merkel, M., Knighton, W. B., Sun, Y., Song, C., Shilling, J. E., Onasch, T. B., Herndon, S. C., Worsnop, D. R., Fast, J. D., Zaveri, R. A., Berg, L. K., Wiedensohler, A., Flowers, B. A., Dubey, M. K., and Subramanian, R.: Characterization of submicron particles influenced by mixed biogenic and anthropogenic emissions using high-resolution aerosol mass spectrometry: results from CARES, Atmos. Chem. Phys., 12, 8131-8156, doi:10.5194/acp-12-8131-2012, 2012.

Setyan, A., Song, C., Merkel, M., Knighton, W. B., Onasch, T. B., Canagaratna, M. R., Worsnop, D. R., Wiedensohler, A., Shilling, J. E., and Zhang, Q.: Chemistry of new particle growth in mixed urban and biogenic emissions - insights from CARES, Atmos. Chem. Phys., 14, 6477-6494, doi:10.5194/acp-14-6477-2014, 2014.

Shilling, J. E., Zaveri, R. A., Fast, J. D., Kleinman, L., Alexander, M. L., Canagaratna, M. R., Fortner, E., Hubbe, J. M., Jayne, J. T., Sedlacek, A., Setyan, A., Springston, S., Worsnop, D. R., and Zhang, Q.: Enhanced SOA formation from mixed anthropogenic and biogenic emissions during the CARES campaign, Atmos. Chem. Phys., 13, 2091-2113, doi:10.5194/acp-13-20912013, 2013.

Tsigaridis, K., Daskalakis, N., Kanakidou, M., Adams, P. J., Artaxo, P., Bahadur, R., Balkanski, Y., Bauer, S. E., Bellouin, N., Benedetti, A., Bergman, T., Berntsen, T. K., Beukes, J. P., Bian, H., Carslaw, K. S., Chin, M., Curci, G., Diehl, T., Easter, R. C., Ghan, S. J., Gong, S. L., Hodzic, A., Hoyle, C. R., Iversen, T., Jathar, S., Jimenez, J. L., Kaiser, J. W., Kirkevåg, A., Koch, D., Kokkola, H., Lee, Y. H., Lin, G., Liu, X., Luo, G., Ma, X., Mann, G. W., Mihalopoulos, N., Morcrette, J. J., Müller, J. F., Myhre, G., Myriokefalitakis, S., Ng, N. L., O'Donnell, D., Penner, J. E., Pozzoli, L., Pringle, K. J., Russell, L. M., Schulz, M., Sciare, J., Seland, Ø., Shindell, D. T., Sillman, S., Skeie, R. B., Spracklen, D., Stavrakou, T., Steenrod, S. D., Takemura, T., Tiitta, P., Tilmes, S., Tost, H., van Noije, T., van Zyl, P. G., von Salzen, K., Yu, F., Wang, Z., Wang, Z., Zaveri, R. A., Zhang, H., Zhang, K., Zhang, Q., and Zhang, X.: The AeroCom evaluation and intercomparison of organic aerosol in global models, Atmos. Chem. Phys., 14, 10845-10895, doi:10.5194/acp-1410845-2014, 2014

Virkkula, A., Ahlquist, N. C., Covert, D. S., Arnott, W. P., Sheridan, P. J., Quinn, P. K., and Coffman, D. J.: Modification, calibration and a field test of an instrument for measuring light absorption by particles, Aerosol Sci. Tech., 39, 68-83, doi:10.1080/027868290901963, 2005.

Wang, W., Rood, M. J., Carrico, C. M., Covert, D. S., Quinn, P. K., and Bates, T. S.: Aerosol optical properties along the northeast coast of North America during the New England Air Quality Study - Intercontinental Transport and Chemical Transformation 2004 campaign and the influence of aerosol composition, J. Geophys. Res.-Atmos., 112, D10S23, doi:10.1029/2006JD007579, 2007.
Warneke, C., McKeen, S. A., de Gouw, J. A., Goldan, P. D., Kuster, W. C., Holloway, J. S., Williams, E. J., Lerner, B. M., Parrish, D. D., Trainer, M., Fehsenfeld, F. C., Kato, S., Atlas, E. L., Baker, A., and Blake, D. R.: Determination of urban volatile organic compound emission ratios and comparison with an emissions database, J. Geophys. Res.-Atmos., 112, D10S47, doi:10.1029/2006JD007930, 2007.

Warneke, C., de Gouw, J. A., Edwards, P. M., Holloway, J. S., Gilman, J. B., Kuster, W. C., Graus, M., Atlas, E., Blake, D., Gentner, D. R., Goldstein, A. H., Harley, R. A., Alvarez, S., Rappenglueck, B., Trainer, M., and Parrish, D. D.: Photochemical aging of volatile organic compounds in the Los Angeles basin: Weekday-weekend effect, J. Geophys. Res.-Atmos., 118, 50185028, doi:10.1002/jgrd.50423, 2013.

Yang, M., Howell, S. G., Zhuang, J., and Huebert, B. J.: Attribution of aerosol light absorption to black carbon, brown carbon, and dust in China - interpretations of atmospheric measurements during EAST-AIRE, Atmos. Chem. Phys., 9, 2035-2050, doi:10.5194/acp-9-2035-2009, 2009.

Zaveri, R. A., Shaw, W. J., Cziczo, D. J., Schmid, B., Ferrare, R. A., Alexander, M. L., Alexandrov, M., Alvarez, R. J., Arnott, W. P., Atkinson, D. B., Baidar, S., Banta, R. M., Barnard, J. C., Beranek, J., Berg, L. K., Brechtel, F., Brewer, W. A., Cahill, J. F., Cairns, B., Cappa, C. D., Chand, D., China, S., Comstock, J. M., Dubey, M. K., Easter, R. C., Erickson, M. H., Fast, J. D., Floerchinger, C., Flowers, B. A., Fortner, E., Gaffney, J. S., Gilles, M. K., Gorkowski, K., Gustafson, W. I., Gyawali, M., Hair, J., Hardesty, R. M., Harworth, J. W., Herndon, S., Hiranuma, N., Hostetler, C., Hubbe, J. M., Jayne, J. T., Jeong, H., Jobson, B. T., Kassianov, E. I., Kleinman, L. I., Kluzek, C., Knighton, B., Kolesar, K. R., Kuang, C., Kubátová, A., Langford, A. O., Laskin, A., Laulainen, N., Marchbanks, R. D., Mazzoleni, C., Mei, F., Moffet, R. C., Nelson, D., Obland, M. D., Oetjen, H., Onasch, T. B., Ortega, I., Ottaviani, M., Pekour, M., Prather, K. A., Radney, J. G., Rogers, R. R., Sandberg, S. P., Sedlacek, A., Senff, C. J., Senum, G., Setyan, A., Shilling, J. E., Shrivastava, M., Song, C., Springston, S. R., Subramanian, R., Suski, K., Tomlinson, J., Volkamer, R., Wallace, H. W., Wang, J., Weickmann, A. M., Worsnop, D. R., Yu, X. Y., Zelenyuk, A., and Zhang, Q.: Overview of the 2010 Carbonaceous Aerosols and Radiative Effects Study (CARES), Atmos. Chem. Phys., 12, 7647-7687, doi:10.5194/acp-12-7647-2012, 2012.

Zelenyuk, A., Imre, D., Nam, E. J., Han, Y. P., and Mueller, K.: ClusterSculptor: Software for expert-steered classification of single particle mass spectra, Int. J. Mass Spectrom., 275, 1-10, doi:10.1016/j.ijms.2008.04.033, 2008.

Zelenyuk, A., Yang, J., Choi, E., and Imre, D.: SPLAT II: An Aircraft Compatible, Ultra-Sensitive, High Precision Instrument for In-Situ Characterization of the Size and Composition of Fine and Ultrafine Particles, Aerosol Sci. Tech., 43, 411-424, doi:10.1080/02786820802709243, 2009.

Zhang, Q., Jimenez, J. L., Canagaratna, M. R., Ulbrich, I. M., Ng, N. L., Worsnop, D. R., and Sun, Y. L.: Understanding atmospheric organic aerosols via factor analysis of aerosol mass spectrometry: a review, Anal. Bioanal. Chem., 401, 3045-3067, doi:10.1007/s00216-011-5355-y, 2011. 